\title{
Redescriptions of Neanthes Kinberg, 1865 (Annelida: Errantia: Nereididae) species from worldwide regions
}

\author{
Tulio F. VILLALOBOS-GUERRERO ${ }^{\circledR 1,3, *}$, Jyothi KARA ${ }^{\circledR 2}$ \& Izwandy IDRIS ${ }^{\circledR} 3$ \\ ${ }^{1}$ Depto. Sistemática y Ecología Acuática, El Colegio de la Frontera Sur, Chetumal, \\ Quintana Roo, 77000, Mexico. \\ ${ }^{2}$ Research and Exhibitions Department, Iziko Museums of South Africa, 25 Queen Victoria St, \\ Gardens, Cape Town, 8001, South Africa. \\ ${ }^{1,3}$ South China Sea Repository and Reference Centre, Institute of Oceanography and Environment, \\ Universiti Malaysia Terengganu, 21030, Kuala Nerus, Terengganu, Malaysia. \\ *Corresponding author: tulio1786@msn.com \\ 2Email: jyothi.kara@gmail.com \\ 33Email: izwandy.idris@umt.edu.my \\ ${ }^{1}$ urn:Isid:zoobank.org:author:A756BFA6-4B9B-4B1A-9806-018570BB1ED5
${ }^{2}$ urn:Isid:zoobank.org:author:95F43DEE-D3BF-400C-A4B7-462B34A2AC71
${ }^{3}$ urn:Isid:zoobank.org:author:8CD057BB-C667-4499-A6E7-CE324B96B467
}

\begin{abstract}
The present study redescribes four species of Neanthes Kinberg, 1865 (Nereididae de Blainville, 1818) based on their type specimens collected from different worldwide localities: Neanthes chilkaensis (Southern, 1921) from India, N. galetae (Fauchald, 1977) from Panama, N. helenae (Kinberg, 1865 ) from St Helena Island, and N. mossambica (Day, 1957) from Mozambique. The morphology of the types was re-examined for the first time after the species were originally described, and incorporated the recent improvements in the standards and terminology for describing nereidid features. The arrangement of paragnaths on area VI stood out among the diagnostic features used to distinguish these four species. Neanthes chilkaensis and $N$. helenae are the unique nereidids bearing p-bar paragnaths on the area VI. Both species are also distinctive as the former species only exhibited p-bar paragnaths on the area VIIVIII and the latter ventrolateral projections on the apodous segment. Further examination revealed that $N$. nanciae (Day, 1949) from St Helena is a junior synonym of $N$. helenae. Moreover, $N$. galetae and $N$. mossambica are distinguishable from other species also by the development of dorsal cirri, neuropodial postchaetal lobe and ventral ligule, the presence/absence of merged paragnaths on area IV, paired oesophageal caeca, among other features. This study has further contributed to the morphological delimitation of the species in Neanthes as a first step towards revising the genus.
\end{abstract}

Keywords. Character, morphology, polychaete, synonymy, taxonomy.

Villalobos-Guerrero T.F., Kara J. \& Idris I. 2021. Redescriptions of Neanthes Kinberg, 1865 (Annelida: Errantia: Nereididae) species from worldwide regions. European Journal of Taxonomy 760: 101-135.

https://doi.org/10.5852/ejt.2021.760.1443 


\section{Introduction}

Nereididae de Blainville, 1818 is a common annelid family with a high number of valid taxa comprising 47 genera and 693 species (de León-González et al. 2020). Neanthes Kinberg, 1865 stands out for being one of the most speciose, common and taxonomically problematic nereidid genera. It comprises 80 accepted taxa distributed from tropical to polar regions of both hemispheres (Villalobos-Guerrero \& Idris 2021), with species living in freshwater (Southern 1921) to abyssal zones (deepest record $5260 \mathrm{~m}$; Hartmann-Schröder 1975), inhabiting all types of natural substratum (sediments, wood, rocky fragments, shelly sand, coral rubble, foraminifera ooze), dwelling among sessile (algal holdfasts, algae, seagrassbeds, corals, oysters, sponges) or dead organisms (whale carcass), co-existing in symbiosis (molluscs, hermit crabs), and residing on structures of several anthropogenic marine zones (farms, marinas, harbours) (e.g., Day 1967; Hutchings \& Turvey 1982; Wilson 1984; Wu et al. 1985; Khlebovich 1996; Shimabukuro et al. 2017; Hsueh 2019a).

Neanthes is currently an artificial genus with polyphyletic origin (see Bakken \& Wilson 2005) that presents problematic differences with other similar genera, such as Hediste Malmgren, 1867, Nereis Linnaeus, 1758, Perinereis Kinberg, 1865 and Simplisetia Hartmann-Schröder, 1981 (HartmannSchröder 1996; Glasby et al. 2011; Villalobos-Guerrero \& Idris 2021; Villalobos-Guerrero et al. 2021). This has caused a continuous extension of the genus diagnosis to include species that cannot be assigned to other nereidid genera with conical paragnaths and spinigerous notochaetae only (e.g., Glasby et al. 2011; Hsueh 2019a, 2019b; Ibrahim et al. 2019), but whose overall morphology is distinctly different from the type species of the genus, Neanthes vaalii Kinberg, 1865. Several studies have attempted to reduce this heterogeneity by transferring distinct species to other genera (Bakken 2007; Sato 2013; Villalobos-Guerrero \& Carrera-Parra 2015; Villalobos-Guerrero 2019; Villalobos-Guerrero \& Idris 2020; Villalobos-Guerrero et al. 2021). Nonetheless, Neanthes remains poorly understood and, thus, is in urgent need of accurate morphological delimitation of the species that aids to redefine the genus through a comprehensive revisionary work (Pamungkas \& Glasby 2015; Bakken et al. 2018; Ibrahim et al. 2019; Sato 2020; Davenport et al. 2020; Villalobos-Guerrero \& Idris 2021; Villalobos-Guerrero et al. 2021).

In the present study, four species that are currently placed in Neanthes are redescribed based on type material from isolated localities in India, Panama, Mozambique and St Helena Island. This study aims to provide more morphological delimitations of the species within the genus Neanthes.

\section{Material and methods}

The type materials examined in this study are deposited in the following museums.

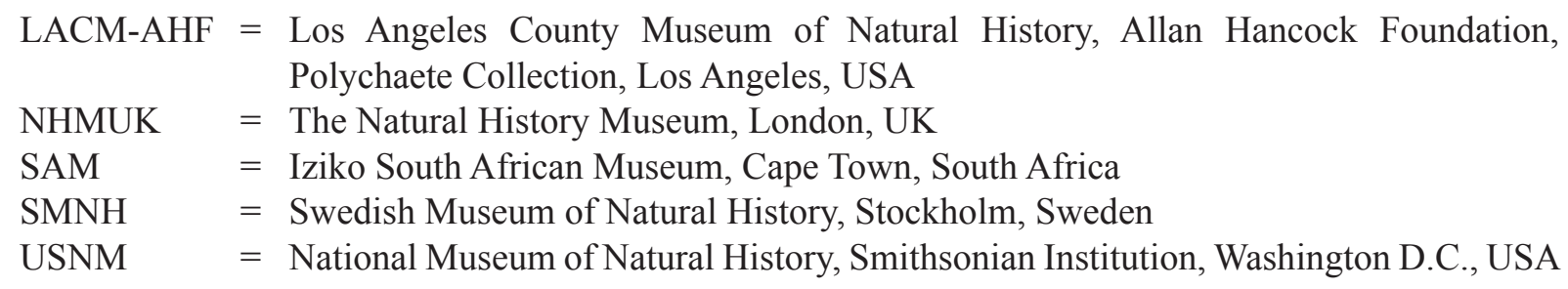

The total length (TL), length from the distal end of prostomium to chaetiger 15 (L15), and body width at chaetiger 15 excluding parapodia (W15) were measured; and the total number of chaetigers was counted for complete specimens. Denticles on the jaws and paragnaths on unpaired and paired sides (denoted as 'a' for left and 'b' for right) of pharyngeal areas were counted (range: min-max). Features of non-everted pharynx were observed by conducting a longitudinal dissection in the mid-ventral oral region. Parapodia were dissected and mounted on glass slides to examine parapodial features. Decimal 
numbers are used for practical purposes when measurements between two structures exceeded one unit (e.g., 1.2 times, 2.5 times, twice); whereas written fractions were used when those measurements were less than one unit (e.g., half, two-thirds, four-fifths).

Light microscopy observations were carried out using both stereo and compound microscopes. Specimens were photographed using a digital camera (Nikon D5100) mounted on the eyepiece of each microscope with a portable microscope adaptor. Around 15-20 photos were stacked to improve the visual depth of field using Helicon Focus ${ }^{\circledR} 6$ (Method C). The figure backgrounds were cleaned and darkened or lightened as necessary, and the final figures assembled in plates using Adobe Photoshop ${ }^{\circledR}$ CS6.

Descriptions of the species are based upon one single primary type morphology unless otherwise stated. Variations for the remaining type material are indicated in parentheses. The relative extension of parapodial structures and the relative width of ligules and lobes were described following recent studies (Villalobos-Guerrero \& Carrera-Parra 2015; Conde-Vela 2018). However, the dorsal cirri were measured considering the length of the proximal region of dorsal ligules, whereas the distal region of dorsal ligules was measured with regard to the length of the proximal region of dorsal ligules (Villalobos-Guerrero 2019).

The nereidid parapodial terminology and standardised definitions of the articulations of chaetae by Villalobos-Guerrero \& Bakken (2018) were followed. The size of falciger blades ( $B / A$ ratio) and the length of its serrated edge concerning the total blade length were described following Bakken \& Wilson (2005) and Glasby \& Hsieh (2006), respectively. The paragnaths terminology of Bakken et al. (2009), partially readapted by Conde-Vela (2018), and the characterisation of the jaws by Jansonius \& Craig (1971), were used. Finally, the description of the pharynx arrangement at the dorsal areas of the oral ring, namely 'area VI-V-VI ridge pattern', is based on Villalobos-Guerrero (2019).

\section{Results}

Phylum Annelida Lamarck, 1802

Class Pleistoannelida Struck, 2011

Subclass Errantia Audouin \& Milne-Edwards, 1832

Order Phyllodocida Dales, 1962

Family Nereididae de Blainville, 1818

Genus Neanthes Kinberg, 1865

Neanthes Kinberg, 1865: 171.

\section{Type species}

Neanthes vaalii Kinberg, 1865, by subsequent designation of Hartman (1954: 27).

\section{Remarks}

The definition of the polyphyletic genus Neanthes introduced earlier by Bakken \& Wilson (2005) through morphological phylogenetic analysis of Nereidinae sensu Fitzhugh (1987) and modified by Glasby (2015) and Villalobos-Guerrero \& Idris (2021) is followed in the present study. For further details on the current taxonomic situation of the genus, see Davenport et al. (2020) and VillalobosGuerrero \& Idris (2021). The four species here morphologically delimited are still retained in Neanthes considering that genus definition. 
Neanthes chilkaensis (Southern, 1921)

Fig. 1

Nereis (Nereis) chilkaensis Southern, 1921: 52-54, pl. 22, fig. 8a-r, text-fig. 4a-c [type locality: Chilika Lake, India].

Nereis chilkaensis - Fauvel 1932: 94-95; 1940: 258; 1953: 185-186, fig. 94a-c.

Neanthes chilkaensis - Hartman 1959: 250; 1974: 618. — Fauchald 1972: 409 (group IIB 1). — Wilson 1984: 225 (group IIB 1) (all previous in species list). — Sunder Raj \& Sanjeeva Raj 1987: 92, pl. 3 fig. 7. - Nesemann \& Sharma 2007: 106, 110, pl. 29 figs 1-2. — Villalobos-Guerrero \& Idris 2021: 559 (table 1), 561 (table 2), 564 (table 3).

Nereis (Neanthes) chilkaensis - Misra et al. 1987: 72. — Nageswara Rao 1995: 324-325.

\section{Type material}

Lectotype (hereby designated)

INDIA • atokous; Orissa, Chilika Lake, "Maludaikuda" [now Maladeikuda] Island; Chilka Lake Survey leg.; NHMUK 1938.5.7.27.

\section{Comparative material}

Syntypes of Neanthes indica brunnea (Day, 1957)

MOZAMBIQUE • 2 specs; Inhambane, Morrumbene Estuary; J.H. Day leg.; NHMUK 1961.16.23 • 1 atokous; same collection data as for preceding; SAM-A-20983.

\section{Description}

COlOUR AND MEASUREMENTS. Lectotype atokous, complete, in good condition, $43 \mathrm{~mm} \mathrm{TL}, 12.2 \mathrm{~mm}$ L15, $2 \mathrm{~mm} \mathrm{W15,} \mathrm{with} 74$ chaetigers. Body colour brownish, with brown pigmentation in dorsum of prostomium and palps, and present throughout in dorsum and venter of segments (Fig. 1A-B).

Prostomium. Campanulate, 1.4 times longer than wide (Fig. 1B); anterior end broad, distally complete; anterolateral gap beside palpophore broad, twice as wide as antennal diameter; dorsal groove distinct, shallow, running mid-subdistally. Nuchal organs barely exposed, broad, 1.5 times as wide as diameter of posterior pair of eyes.

Palpophores. Sub-conical, as wide as long (Fig. 1B), as long as three-fifths of entire prostomium; with distinct sub-distal transverse groove. Palpostyles ovoid, thick, with diameter as wide as one-third of palpophore.

Antennae. Tapered, slender, long, extending forwards beyond tip of palpophore and posteriorly to halflength of prostomium; antennae well separated, with gap 1.2 times as wide as basal diameter of antennae.

EYES. Paired eyes blackish, arranged in a trapezoid form; gap between both pairs two-fifths as wide as diameter of posterior pair of eyes (Fig. 1B); anterior pair of eyes rounded, 1.5 times as wide as basal diameter of antennae, gap between both eyes 3 times as wide as diameter of eyes, with lens slightly distinct, dark, covering $20 \%$ of eye; posterior pair of eyes rounded, 1.2 times as wide as basal diameter of antennae, with lens barely distinct, dark, placed in middle of eye and covering $15 \%$ of it.

Apodous Anterior Segment. Segment 2.5 times wider than long, 1.6 times as long as chaetiger 1, with flattening anterior margin, dorsum without marked transverse wrinkle. 
TENTACUlar CIRRI. Slender, multi-articulated (Fig. 1B); postero-dorsal cirri extending posteriorly to chaetiger 5, twice as long as antero-dorsal cirri; antero-dorsal cirri extending posteriorly to chaetiger 2; postero-ventral cirri extended over opposite side of prostomium; antero-ventral cirri as long as posteroventral cirri and extending beyond 1.3 times length of palpophore; dorsal cirrophores cylindrical, ventral cirrophores ring-shaped, postero-dorsal cirrophores as long as antero-dorsal cirrophores, antero-ventral cirrophores twice as wide as postero-ventral cirrophores.

Pharynx. Non-everted, previously dissected. Jaws not dissected, with 10 well-developed and blunt denticles; pulp cavity with two canals. Brownish paragnaths on maxillary and oral rings (Fig. 1C), except reddish on areas VII-VIII, consisting of conical and p-bars; merged paragnaths and plate-like basements absent. Area I: 8, irregular patch of uneven cones, distal ones smaller; areas IIa: 18 and IIb: 22 , three slightly regular rows of uneven cones in eyebrow-shaped patch, cones in outer-most row larger (Fig. 1C); area III: 29, four irregular rows of uneven cones in sub-rectangular patch, without distinct laterally-isolated cones, distal cones smaller (Fig. 1C); areas IVa: 35 and IVb: 37, pear-shaped patch with proximal half consisting of four irregular rows and distal half with three slightly regular rows of uneven cones (Fig. 1C); area V: 4, two oblique rows of two small, worn, conical paragnaths, near but placed behind level of paragnaths on area VI (Fig. 1C); areas VIa: 5 and VIb: 7, one transverse row of distal, uneven p-bars becoming shorter outwards (two in VIa, four in VIb; Fig. 1C-D) and one irregular patch of proximal, even cones (two in VIa and VIb; Fig. 1C-D); areas VII-VIII: 51, two bands of p-bars ventrally well separated, with anterior and posterior bands consisting each of two transversely aligned rows, furrow row and ridge row with one p-bar on each region (Fig. 1C). Areas VI-V-VI ridge pattern, $\lambda$-shaped. Gap between area VI and areas VII-VIII narrow, as wide as palpostyle.

Paired oesophageal caeca. Present.

PARAPODIA. Without glandular, dorsal patches. Notopodia consisting of dorsal cirrus, dorsal ligule (distal and proximal), notopodial prechaetal lobe, and median ligule in biramous parapodia. Neuropodia consisting of neuroacicular ligule with inferior and postchaetal lobes, ventral ligule, and ventral cirrus; superior lobe absent throughout.

DoRSAL CIRRI. Cirriform, long, extending markedly beyond distal region of dorsal ligule throughout (Fig. 1E-I); dorsal cirri 3.5-4 times as long as proximal region of dorsal ligule in anteriormost and anterior parapodia (Fig. 1E-F), 4-5 times as long as that in middle parapodia (Fig. 1G-H), 3 times as long as that in posterior (Fig. 1I) and posteriormost parapodia; attached basally to dorsal ligule in anteriormost parapodia (Fig. 1E), one-third in anterior parapodia (Fig. 1F), medially in middle parapodia (Fig. 1G-H), three-quarters in posterior (Fig. 1I) and posteriormost parapodia.

Dorsal ligule. Proximal region even towards posterior end; shorter than distal region of dorsal ligule in anteriormost and anterior parapodia (Fig. 1E-F), as long as that in following parapodia (Fig. 1G-I); glandular patch small, sub-oval, present on the base of dorsal cirri, more distinct in middle and posterior parapodia (Fig. 1H-I). Distal region well developed with similar length throughout (Fig. 1E-I); bluntly conical in anterior parapodia, conical in following parapodia, smaller than median ligule throughout; projecting distinctly beyond notoacicula throughout; one whitish, cylindrical, glandular patch throughout.

Notopodial prechaetal lobe. Present from parapodia 5 to parapodia 18 (Fig. 1F); bluntly conical, half as long as median ligule in anterior parapodia, then reducing and tapering gradually to notoacicular process that disappears in about parapodia 25 .

MEdian Ligule. Bluntly conical in anterior parapodia (Fig. 1F), conical in following parapodia (Fig. 1GI), becoming slightly longer and narrower from middle parapodia towards posterior end. 
Neuroacicular ligule. Smaller than ventral ligule in anteriormost parapodia (Fig. 1E), as long as in following parapodia (Fig. 1F-I), 1.5 times as wide as ventral ligule throughout.

Neuropodial inferior LOBE. Slightly developed and longer than neuroacicular ligule in first five parapodia, absent in following chaetigers.

Neuropodial postchaetal LOBE. Present throughout; digitiform in anteriormost parapodia, bluntly conical in anterior parapodia, conical in following parapodia; slightly longer than neuroacicular ligule in anteriormost and posterior parapodia (Fig. 1E, I), as long as that in remaining parapodia.

VeNTRAL LIGULE. Well developed throughout; bluntly conical, thick in anteriormost and anterior parapodia (Fig. 1E-F), conical and slender in following chaetigers; smaller than median ligule throughout, more distinct in posterior parapodia (Fig. 1I); extending beyond distal region of dorsal ligule in parapodia 1 and 2 (Fig. 1E).

Ventral CIRRI. Cirriform, slender; two-thirds as long as ventral ligule in anteriormost and anterior parapodia (Fig. 1E-F), one-third as long as that in following chaetigers (Fig. 1G, I).

ACICULAE. Black, with basal end uncoloured. Notoaciculae absent in first two chaetigers (Fig. 1E). Neuroaciculae extending beyond distal end of notoaciculae throughout, more distinct in anteriormost and anterior parapodia (Fig. 1F), with proximal half 1.2-1.4 times as wide as notoaciculae.

NotochaEtAE. All homogomph spinigers (Fig. 1J); 14-15 spinigers present in anterior parapodia, 9-10 spinigers in middle parapodia, 4 spinigers in posterior parapodia and 2 spinigers in posteriormost parapodia.

Supracicular neurochaetae. Mostly broken or with blades missing; consisting of homogomph spinigers (Fig. 1K) and heterogomph falcigers, both present throughout.

Subacicular neurochaEtae. Mostly broken or with blades missing; consisting of heterogomph spinigers (Fig. 1L) and heterogomph falcigers (Fig. 1M), both present throughout.

BLADES. Both homogomph (Fig. 1J-K) and heterogomph (Fig. 1L) spinigers with blades finely serrated towards toothed edge, evenly spaced, long $(B / A$ ratio $8-17.5)$. Heterogomph falcigers with blades slender and of medium size (1.2-1.6), convex, terminal tooth blunt with inconspicuous tendon; serrations present in about two-fifths (0.4-0.45) of total blade length (Fig. 1M). Shaft of supracicular falcigers thicker than subacicular ones in posterior parapodia; camerated, with cavity divided sub-distally into two longitudinal partitions.

Pygidium. Distinctly projected, bluntly conical, as long as wide, with anal cirri as long as last 9 chaetigers; cirrophores of anal cirri barely developed (Fig. 1A).

\section{Remarks}

Neanthes chilkaensis was not compared with other species in the original description. Among all the currently known species of Neanthes, $N$. chilkaensis resembles $N$. indica brunnea and N. mossambica (Day, 1957), both from Mozambique, and N. talehsapensis (Fauvel, 1932) from the Songkhla Lake in Thailand. These species share a proximal region of dorsal ligule of similar size throughout the body (or slightly enlarged in posterior parapodia), presence of neuropodial postchaetal and notopodial prechaetal lobes at least in some anterior chaetigers, absence of neuropodial superior lobes, areas VII-VIII with two well-defined bands of more than 20 paragnaths, and area I with two or more paragnaths (see VillalobosGuerrero \& Idris 2021: table 2). 

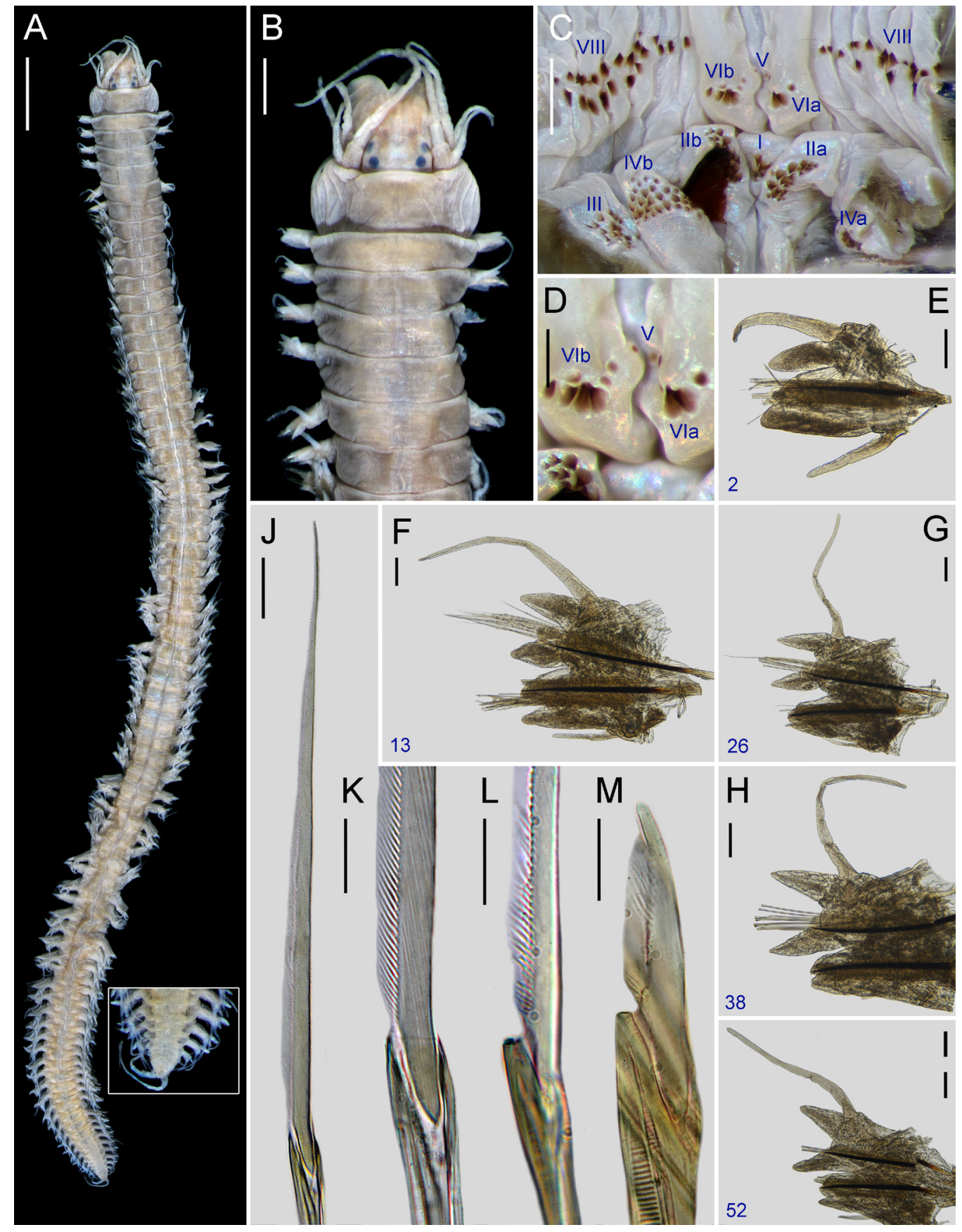

Fig. 1. Neanthes chilkaensis (Southern, 1921). Lectotype (NHMUK 1938.5.7.27) from Chilika Lake, Orissa, India, atokous. A. Entire body in dorsal view (inset: approach of pygidium). B. Anterior end in dorsal view. C. Non-everted pharynx in ventral view. D. Dorsum of oral ring of non-everted pharynx in ventral view. E. Left parapodium from chaetiger 2 in posterior view. F. Left parapodium from chaetiger 13 in posterior view. G. Right parapodium from chaetiger 26 in anterior view. H. Right parapodium from chaetiger 38 in anterior view with ventral cirri contracted and hidden behind the neuroacicular ligule. I. Parapodium from chaetiger 52 in anterior view. J. Homogomph spiniger from notochaetae (chaetiger 13). K. Homogomph spiniger from supracicular neurochaetae (chaetiger 13). L. Heterogomph spiniger from subacicular neurochaetae (chaetiger 2). M. Heterogomph falciger from subacicular neurochaetae (chaetiger 13). Roman numerals refer to the areas and Arabic numbers to chaetigers. Scale bars: $\mathrm{A}=$ $3 \mathrm{~mm} ; \mathrm{B}=1 \mathrm{~mm} ; \mathrm{C}=0.5 \mathrm{~mm}$; D-I $=0.2 \mathrm{~mm} ; \mathrm{J}-\mathrm{M}=20 \mu \mathrm{m}$. 
Nonetheless, $N$. chilkaensis is distinguishable from the species mentioned above according to the following diagnostic features: (I) the presence of p-bars on area VI, in contrast to its absence in those species; (II) the presence of solely p-bars on areas VII-VIII, in comparison to either conical only or both p-bars and conical ones in those species; (III) the multi-articulated tentacular cirri, in contrast to smooth ones in those species; (IV) four paragnaths on the area $\mathrm{V}$ of the pharynx, in comparison to none in those species; (V) a higher number of paragnaths on area III (29), in contrast to a lower number in $N$. indica brunnea (5-9) and N. talehsapensis (14); (VI) 5-7 paragnaths on area VI of the pharynx, in comparison to one in N. mossambica; (VII) the presence of oesophageal caeca, in contrast to its absence in N. mossambica; (VIII) aciculae mostly black, in contrast to pale coloured ones in N. talehsapensis; (IX) the notopodial prechaetal lobe distinctly smaller than median ligule throughout, in comparison to a subequal in anterior chaetigers of $N$. talehsapensis; (X) the dorsal cirri extending markedly beyond distal region of dorsal ligule, in contrast to those not extending beyond it in $N$. indica brunnea; (XI) the presence of a neuropodial postchaetal lobe throughout, in comparison to it being present in anterior chaetigers only in $N$. indica brunnea; (XII) the blade of heterogomph falcigers with blunt terminal tooth and inconspicuous tendon in middle and posterior parapodia, in contrast to hammer-headed terminal tooth and distinct tendon in $N$. indica brunnea; (XIII) the antennae well separated from each other, in comparison to those closely together in $N$. indica brunnea; and finally (XIV) the dorsum of segments with pigmentation bands, in contrast to it being present only in apodous segment in $N$. indica brunnea.

The species was described and illustrated in detail by Southern (1921) and placed within the genus Nereis using specimens in immature and reproductive stages collected from the southern half of the Chilika Lake, India. The original description is a combination of the available specimens' morphology, which consisted of four epitokous (two females and males) specimens and seemingly four atokous specimens with different lengths and numbers of chaetigers: $92 \mathrm{~mm}, 81$ chaet.; $65 \mathrm{~mm}, 84$ chaet.; $56 \mathrm{~mm}, 66$ chaet.; $44 \mathrm{~mm}, 81$ chaet. However, the atokous specimen examined here does not match the size and number of chaetigers stated originally for those specimens. Southern (1921) used the specimen with $56 \mathrm{~mm}$ and 66 chaetigers to describe and illustrate the structures associated with the parapodia 1, 10, 50 and 60 , which seems to correspond with one of two syntypes showing traces of desiccation deposited at the Zoological Survey of India (ZEV6281/7; http://www.zsicollections.in/search/ZSI0000004205) but not available for the present study. In general terms, the syntype examined matches the original description of $N$. chilkaensis. Hence, in order to fix the species definition (ICZN 1999, Art. 74.7.3), the specimen NHMUK 1938.5.7.27 is here selected as lectotype (ICZN 1999, Art. 74.1, 74.7.1) and described in detail with illustrations (ICZN 1999, Art. 74.7.2).

Moreover, some variations among the species deserve discussion. Southern (1921) described $N$. chilkaensis without paragnaths on area $\mathrm{V}$, which are present in the lectotype in two oblique rows of four conical paragnaths near but placed behind the level of paragnaths of area VI. According to Southern (1921), the blades of subacicular heterogomph falcigers can wear distally giving two appearances: (I) long, slender, with many teeth; and (II) small, thick, with few teeth. In the syntype, only the first blade type was found possibly because most of the neurochaetae are broken or missing; however, judging Southern's falciger illustrations, the presence of the second type of falciger, as occurs in other species of Neanthes (Villalobos-Guerrero \& Idris 2021; this study), is not disregarded.

The species was transferred to Neanthes by Hartman (1959), most likely founded on her proposal of distinguishing Neanthes from Nereis by the absence of homogomph falcigers (present in the latter genus; Hartman 1940, 1954). The species has been recognised in Neanthes until nowadays (Fauchald 1972; Wilson 1984; Nesemann \& Sharma 2007), sometimes incorrectly treated in the unaccepted subgenus Nereis (Neanthes) (Misra et al. 1987; Nageswara Rao 1995). The species was briefly characterised by Fauvel $(1932,1953)$ from some specimens collected in the type locality and other sites in the east of 
India. Later, Misra et al. (1987) and Nageswara Rao (1995) did the same using specimens exclusively from the Chilika Lake, although the characterisations were very short and incomplete.

Neanthes chilkaensis has been recorded from several localities along the shores of India (Parulekar 1971; Sunder Raj \& Sanjeeva Raj 1987; Nesemann \& Sharma 2007; Markande et al. 2014) and Sri Lanka (de Silva 1965), which were mostly based on Fauvel's $(1932,1940,1953)$ studies from India. These records are considered valid, although re-assessment is needed, especially those from Sri Lanka and the south and west of India.

\section{Distribution}

East India: Chilika Lake (Ossira), Mandras, Pamban (Tamil Nadu) (Fauvel 1932, 1953; Ganapati 1946; Misra et al. 1987; Nageswara Rao 1995); west India: Neendakara (Kerala) (Fauvel 1940), Dabhol, Devgad, Malvan, Mumbai, Vengurla and Vijaydurg (Maharastra) (Markande et al. 2014; Pati et al. 2015); Sri Lanka (de Silva 1965).

\section{Ecology}

Common in muddy estuarine habitats (Misra et al. 1987). In Chilika Lake, living in brackish water under stones, sand above and below high-water mark, amongst algae on the rocks, and in sponges Spongilla Lamarck, 1816 and Laxosuberites Topsent, 1896 (= Hymeniacidon Bowerbank, 1858 sensu van Soest 2020) (Southern 1921). Host of the intestinal gregarine parasite Lecudina ganapatii Vivier, Ormieres \& Tuzet, 1964 [as L. pellucida (von Kölliker, 1848) Mingazzini, 1891] (Ganapati 1946).

\section{Reproduction}

According to Southern (1921), males and females undergo an epitokal metamorphosis but not as developed as in the heteronereis stage. Epitokous specimens were found in January, February and November. Males gyrate in a spiral course on water column to release the sperm.

\section{Neanthes galetae Fauchald, 1977}

Fig. 2

Neanthes galetae Fauchald, 1977: 26-27, fig. 6a-b [type locality: Galeta Island, Colón, Panama].

Neanthes galetae - Wilson 1984: 225 (species list, group IIB). — de León-González et al. 2020: 19 (key). - Villalobos-Guerrero \& Idris 2021: 559 (table 1), 561 (table 2).

\section{Type material}

\section{Holotype}

PANAMA • atokous; Caribbean Sea, Colón, Canal Zone, Galeta Island Reef; 23 Oct. 1970; Smithsonian Tropical Research Institute and A.A. Reimer leg.; intertidal, Laurencia or Acanthophora zones; USNM 53088 .

\section{Paratypes}

PANAMA $\bullet 2$ atokous; same collection data as for holotype; USNM $53089 \bullet 1$ atokous; same collection

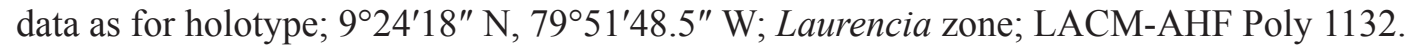

\section{Description}

Colour AND MEASUREMENTS. Holotype atokous, complete, in good condition, 7 (9-14) mm TL, 2.4 (2.54) $\mathrm{mm} \mathrm{L15}, 0.6(0.6-0.9) \mathrm{mm}$ W15, with 52 (56-58) chaetigers. Body colour yellowish, with greyish pigmentation on distal half of prostomium, cirrophores of anal cirri, and present throughout dorsally and ventrally as a transverse, thin line in anterior margin of segments (Fig. 2A-B). 
Prostomium. Pear-shaped, as long as wide (Fig. 2B); anterior end narrow, distally complete; anterolateral gap beside palpophore narrow, three-quarters as wide as antennal diameter; dorsal groove distinct, shallow, running mid-subdistally. Nuchal organs deeply embedded.

Palpophores. Ovoid, 1.6 times wider than long (Fig. 2B), as long as half of entire prostomium; with inconspicuous sub-distal transverse groove. Palpostyles ovoid, thick, with diameter as wide as half of palpophore (Fig. 2B).

AntennAe. Tapered, slender, short, extending forwards to tip of palpophore (Fig. 2B) and posteriorly to one-third length of prostomium; antennae close together, with gap one-quarter as wide as basal diameter of antennae.

EYES. Paired eyes blackish, arranged in a trapezoid form; gap between both pairs one-quarter as wide as diameter of posterior pair of eyes (Fig. 2B); anterior pair of eyes rounded, twice as wide as basal diameter of antennae, gap between both eyes 2.5 times as wide as diameter of eyes, with lens distinct, purplish, covering $30 \%$ of eye; posterior pair of eyes rounded, twice as wide as basal diameter of antennae, with lens distinct, purplish, placed posterolaterally on eye and covering $40 \%$ of it.

Apodous anterior Segment. Segment 2.5 times wider than long, as long as chaetiger 1, with flattening anterior margin, dorsum without marked transverse wrinkle (Fig. 2B).

Tentacular CiRRI. Slender, multi-articulated (Fig. 2B); postero-dorsal cirri extending posteriorly to chaetiger 4 (3), 1.6 times as long as antero-dorsal cirri; antero-dorsal cirri extending posteriorly to between chaetigers 1 and 2 (1-2); postero-ventral cirri extended over half of prostomium; antero-ventral cirri 1.5 times as long as postero-ventral cirri and extending beyond 1.3 times length of palpophore; dorsal cirrophores cylindrical, ventral cirrophores ring-shaped, postero-dorsal cirrophores 1.5 times as long as antero-dorsal cirrophores, antero-ventral cirrophores 1.5 times as wide as postero-ventral cirrophores.

Pharynx. Non-everted, previously dissected. Jaws with distal quarter brownish, remaining yellow amber, 10 well-developed and sharp denticles; pulp cavity with two canals (Fig. 2C-D, paratype). Reddish-brown paragnaths on maxillary and oral rings (Fig. 2C), consisting of conical, p-bars, and merged paragnaths; plate-like basements absent. Area I: 0 (0-1) (Fig. 2C); areas IIa: 9 (9-12) and IIb: $9(8-14)$, two slightly regular rows of uneven cones in eyebrow-shaped patch, cones in outer row larger (Fig. 2C); area III: unknown but one paratype with 12 (5-12) paragnaths in two slightly regular rows of uneven cones in rectangular patch, without distinct laterally-isolated cones, distal row with larger cones; areas IVa: 11 (13-14) and IVb: 13 (11-17), crescent-shaped patch with two slightly regular transverse rows of uneven cones located proximally and four long and slender merged paragnaths (2-4 times longer than wide; Fig. 2C) located distally; area V: 0 (0) (Fig. 2C); areas VIa: 9 (9-11) and VIb: 9 (9-10), one rounded patch of uneven cones, closely together (Fig. 2C); areas VII-VIII: 5 (13-15), one band of uneven cones consisting of two transversely aligned rows (Fig. 2C). Areas VI-V-VI ridge pattern, $\pi$-shaped (Fig. 2C). Gap between area VI and areas VII-VIII narrow, as wide as palpostyle.

Paired oesophageal caeca. Present.

PARAPODIA. With one massive, dorsal, sub-spherical gland present from chaetiger 13 towards posterior end, becoming larger, reaching maximum size from chaetiger 36 (Fig. 2A, H-I). Notopodia consisting of dorsal cirrus, dorsal ligule (distal and proximal), and median ligule in biramous parapodia; notopodial prechaetal lobe absent throughout but as notoacicular process in some parapodia. Neuropodia consisting of neuroacicular ligule, ventral ligule, and ventral cirrus; lobes absent throughout. 
DORSAL CIRRI. Cirriform, thick, medium-sized, extending beyond distal region of dorsal ligule throughout (Fig. 2E, I); dorsal cirri 3-3.5 times as long as proximal region of dorsal ligule in anteriormost and posteriormost parapodia (Fig. 2E, I), 2-2.5 times as long as in remaining parapodia (Fig. 2F-H); attached basally to dorsal ligule in anteriormost parapodia (Fig. 2E), medially in following parapodia (Fig. 2F-I).

Dorsal Ligule. Proximal region even towards posterior end, except faintly humped in middle and posterior parapodia (Fig. 2H-I); shorter than distal region of dorsal ligule in anteriormost parapodia (Fig. 2E), as long as that in following parapodia (Fig. 2F-I); two irregular glandular patches covering partially proximal region of dorsal ligule in anterior parapodia and entirely covering that in following parapodia (Fig. 2G-I). Distal region well developed, becoming narrower towards posterior end; digitiform in anteriormost parapodia (Fig. 2E), bluntly rounded in anterior parapodia (Fig. 2F), conical in following parapodia (Fig. 2G-I), slightly smaller than median ligule throughout; projecting beyond notoacicula throughout; one irregular glandular patch covering entire distal region of dorsal ligule (Fig. 2F-I).

NotoAcicular Process. Present from parapodia 5 to parapodia 20 (Fig. 2F-G), small, blunt.

Median ligule. Digitiform in anteriormost parapodia, bluntly rounded in anterior parapodia (Fig. 2F), conical in following parapodia (Fig. 2G-I), becoming narrower from middle parapodia towards posterior end.

Neuroacicular ligule. Smaller than ventral ligule in anteriormost parapodia (Fig. 2E), as long as in following parapodia (Fig. 2F-I), 1.5 times as wide as ventral ligule throughout.

VeNTRAL LIGULE. Well developed throughout; bluntly conical, thick in anteriormost and anterior parapodia (Fig. 2E-F), conical and slender in following chaetigers; smaller than median ligule throughout; as long as distal region of dorsal ligule in parapodia 1 and 2 (Fig. 2E).

Ventral CIRRI. Cirriform, slender; two-quarters as long as ventral ligule in anteriormost and anterior parapodia (Fig. 2E-F), half as long as in following chaetigers (Fig. 2G-I).

Aciculae. Reddish, with basal end uncoloured. Notoaciculae absent in first two chaetigers (Fig. 2E). Neuroaciculae extending slightly beyond distal end of notoaciculae throughout, with proximal half 1.41.7 times as wide as notoaciculae.

NotochaetaE. All homogomph spinigers; $8-9$ spinigers present in anterior parapodia, $6-7$ spinigers in middle parapodia, $4-5$ spinigers in posterior parapodia and 2 spinigers in posteriormost parapodia.

Supracicular neurochaetae. Consisting of homogomph spinigers (Fig. 2J-K), heterogomph spinigers (Fig. 2J) and heterogomph falcigers (Fig. 2L). Homogomph spinigers present throughout; 1 spiniger present in anteriormost parapodia, 2-4 spinigers in anterior and middle parapodia, 3-4 spinigers in posterior parapodia, 2 spinigers in posteriormost parapodia. Heterogomph spinigers present in first seven parapodia, with 3 spinigers. Heterogomph falcigers present from parapodia 8 to end of body; 2 falcigers present in anterior parapodia, 1-2 falcigers in middle parapodia, 2 falcigers in posterior parapodia, 1 falciger in posteriormost parapodia.

Subacicular neurochaetaE. Consisting of heterogomph spinigers (Fig. 2J) and heterogomph falcigers (Fig. 2M). Heterogomph spinigers present throughout; 4-5 spinigers present in anteriormost and anterior parapodia, 1-2 spinigers in middle parapodia, 1 spiniger in posterior and posteriormost parapodia. Heterogomph falcigers present from parapodia 5 (5-6) to end of body, with 4-5 falcigers in parapodia throughout. 

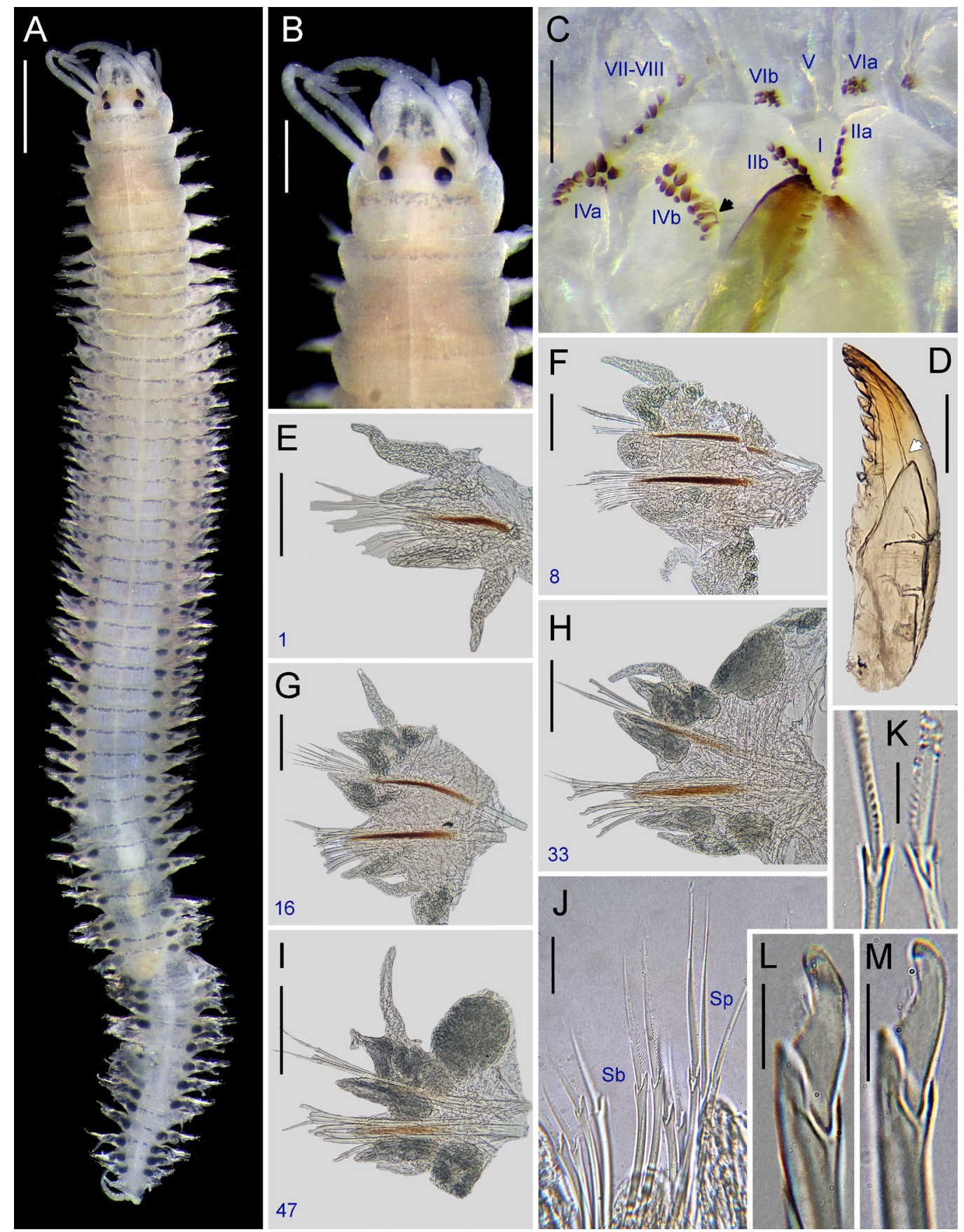

Fig. 2. Neanthes galetae Fauchald, 1977. A-B, E-M. Holotype (USNM 53088) from Galeta Reef, Panama, atokous. C-D. Paratype (USNM 53089) from Galeta Reef, Panama, atokous. A. Entire body in dorsal view. B. Anterior end in dorsal view. C. Non-everted pharynx in ventral view, black arrow indicates merged paragnaths. D. Right jaw in dorsal view, white arrow indicates canals. E. Right parapodium from chaetiger 2 in anterior view. F. Right parapodium from chaetiger 8 in anterior view. G. Right parapodium from chaetiger 16 in anterior view. H. Right parapodium from chaetiger 33 in anterior view. I. Right parapodium from chaetiger 47 in anterior view. J. Supracicular (Sp) and subacicular (Sb) neurochaetae (chaetiger 1). K. Homogomph spiniger from supracicular neurochaetae (chaetiger 47). L. Heterogomph falciger from supracicular neurochaetae (chaetiger 47). M. Heterogomph falciger from subacicular neurochaetae (chaetiger 47). Roman numerals refer to the areas and Arabic numbers to chaetigers. Scale bars: A $=0.5 \mathrm{~mm} ; \mathrm{B}=0.2 \mathrm{~mm} ; \mathrm{C}-\mathrm{I}=0.1 \mathrm{~mm} ; \mathrm{J}=20 \mu \mathrm{m} ; \mathrm{K}-\mathrm{M}=10 \mu \mathrm{m}$. 
BLADES. Both homogomph (Fig. 2J-K) and heterogomph (Fig. 2J) spinigers with blades of medium and long size ( $B / A$ ratio 3.8-9.1), finely serrated towards toothed edge, evenly spaced in anteriormost and anterior parapodia, coarse proximal teeth and notoriously separated in following parapodia (Fig. $2 \mathrm{~K}$ ). Blades of heterogomph falcigers in anterior parapodia slender, convex, medium size ( $B / A$ ratio $1.3-1.7)$, terminal tooth blunt with inconspicuous tendon, serrations present in about half to one-third (0.35-0.46) of total blade length; blades in following parapodia thicker, convex, short ( $B / A$ ratio $0.9-1.1)$, terminal tooth incurved with distinct tendon, serrations present in about one-quarter to one-third (0.25-0.34) of total blade length (Fig. 2L-M). Shaft of supracicular falcigers thicker than subacicular ones in posterior parapodia; camerated, with cavity divided sub-distally into two longitudinal partitions.

PYGIDIUM. Distinctly projected, bluntly conical, as long as wide, with anal cirri as long as last 4 (3-6) chaetigers; cirrophores of anal cirri barely developed.

\section{Remarks}

Among all the currently known species of Neanthes, $N$. galetae from Galeta Island, Panama, resembles $N$. dawydovi (Fauvel, 1937) from Vietnam, N. egregicirrata (Treadwell, 1924) from Antigua in Lesser Antilles, N. hondoensis Khlebovich, 1996 from Japan, N. maculata Wu, Sun \& Yang, 1981 from China, N. mexicana Fauchald, 1972 from the Mexican Pacific, N. papillosa (Day, 1963) from South Africa, and $N$. vandersandei (Horst, 1924) from Indonesia. These eight species share proximal region of the dorsal ligules of similar size across the body (or slightly enlarged in posterior parapodia), absence of notopodial prechaetal, neuropodial postchaetal and superior lobes and subacicular homogomph spinigers, areas VII-VIII with one well-defined band of fewer than 20 paragnaths, area III with less than 20 paragnaths, and the area I with no more than two paragnaths (see Villalobos-Guerrero \& Idris 2021: table 2). Additionally, they are all similar as they possess a pear-shaped prostomium and ovoid palpophores.

Nonetheless, $N$. galetae is easily distinguishable from them all by the following diagnostic features: (I) rounded patch of 9-11 paragnaths on area VI, in contrast to transverse row of up to four paragnaths in $N$. dawydovi, N. egregicirrata, N. maculata, $N$. papillosa and $N$. vandersandei, one paragnath in $N$. mexicana, and none in $N$. hondoensis; (II) the paired eyes of similar size, in contrast to the anterior pair markedly larger than the posterior pair in N. mexicana and N. papillosa; (III) the ventral ligule welldeveloped throughout, in contrast to that markedly reduced in posterior parapodia of $N$. dawydovi; (IV) the dorsum of all segments with transverse pigmentations, in comparison to its absence in chaetiger 2 in N. dawydovi; and (V) dorsal cirri with regular size, in contrast to it being markedly elongated on parapodia 6 in $N$. egregicirrata.

Likewise, $N$. galetae can also be differentiated from $N$. vandersandei in the following features based on its recent redescription (Villalobos-Guerrero \& Idris 2021): (I) the multi-articulated tentacular cirri, in contrast to those smooth in $N$. vandersandei; (II) the presence of merged paragnaths on area IV, in comparison to its absence in N. vandersandei; (III) the presence of paired oesophageal caeca, in contrast to its absence in $N$. vandersandei; (IV) the presence of heterogomph spinigers in a few anterior supracicular neurochaetae, in comparison to its absence throughout in $N$. vandersandei; and (V) the blade of heterogomph falcigers with incurved terminal tooth and distinct tendon in middle and posterior parapodia, in contrast to those with blunt terminal tooth and inconspicuous tendon throughout in N. vandersandei.

The species was described by Fauchald (1977) using eight immature specimens collected from the Panama side of the Caribbean Sea among red algae, although only six of those collected in the Acanthophora and Laurencia zones correspond to the type series. At present, only four types remain (holotype and three paratypes). The type material examined here partially matches the barely-illustrated original description, which was seemingly based on the holotype. Neanthes galetae was described with a higher number of paragnaths in the areas of the maxillary ring (I: 2; II: 20; III: 18; IV: 25) when compared with 
specimens from the type series (I: 0-1; II: 8-14; III: 5-12; IV: 11-17). The dorsal cirri were mentioned as attached basally throughout in the original description, although it is attached medially in the middle and posterior parapodia of the type series. The replacement of homogomph spinigers by heterogomph spinigers in supracicular neurochaetae of posteriormost parapodia stated in the description was not observed in the type material. However, the heterogomph spinigers were observed in a few anteriormost parapodia, which were replaced by heterogomph falcigers in the following parapodia.

Neanthes galetae was not characterised or redescribed previously until this study. The original description includes a short, implicit comparison with four taxa of Neanthes in having a few paragnaths on area VII-VIII: Neanthes agulhana (Day, 1963) from South Africa, N. dawydovi, N. kerguelensis (Mclntosh, 1885) from the Kerguelen Islands, and N. kerguelensis oligodonta (Augener, 1913) from Australia. They were distinguished by paragnaths occurring on area I, although variations overlap in the species (see Villalobos-Guerrero \& Idris 2021; this study). The subspecies is not considered valid presently (Wilson 1984), and the differences with $N$. dawydovi were mentioned above. Neanthes galetae is easily distinguished from both $N$. agulhana and $N$. kerguelensis by the lack of notopodial prechaetal lobe (present in those species) and the rounded patch of 9-11 paragnaths on area VI (transverse row of up to 4 paragnaths in N. agulhana and 0-1 paragnath in N. kerguelensis). Neanthes galetae is also different from $N$. kerguelensis by the lack of neuropodial postchaetal lobe and subacicular homogomph spinigers (both present in N. kerguelensis).

The species has also been recorded from the Pacific part of El Salvador (Planas et al. 2013) and Colombia (Jaime et al. 1999) in ecological studies. However, they are considered doubtful until a re-examination of the voucher material is performed.

\section{Distribution}

Panama: Galeta Island, Colón (Caribbean Sea).

\section{Ecology}

Intertidal among red algae of the genera Acanthophora J.V.Lamour. and Laurencia J.V.Lamour. and present among the seagrass Thalassia Banks ex König (Fauchald 1977) and Halodule Endl. (Vásquez Montoya \& Thomassin 1983).

\section{Reproduction}

Unknown.

Neanthes helenae (Kinberg, 1865)

Figs 3-4

Neanthes helenae Kinberg, 1865: 172 [type locality: Jamestown, Saint Helena Island].

Nereis (Neanthes) nanciae Day, 1949: 445, fig. 4a-h.

Neanthes helenae - Hartman 1959: 250 (species list). — Wilson 1984: 225 (species list). — VillalobosGuerrero \& Idris 2021: 559 (table 1), 561 (table 2).

Neanthes nanciae - Hartman 1959: 250. — Fauchald 1972: 410 (group IIB 2a). — Wilson 1984: 226 (group IIB 2a) (all in species list).

\section{Type material}

\section{Syntypes}

ST HELENA -2 atokous (one 9 ); Jamestown; $16^{\circ} 00^{\prime} \mathrm{S}, 5^{\circ} 40^{\prime} \mathrm{W} ; 27.5 \mathrm{~m}$ depth; Eugenie Expedition 1851-53 leg.; sta. 173; poor condition; SMNH Type-457 1 spec., permanent slide of atokous $P$; same 
data as for syntypes; parapodium $24^{\text {th }}$; SMNH Type-457, housed at the NHMUK [apparently loaned to Arthur Willey in this museum].

\section{Type material of Nereis (Neanthes) nanciae Day, 1949}

\section{Holotype}

ST HELENA 1 atokous; Dockyard, Crown Point and Jamestown; $73 \mathrm{~m}$ depth; some date between 7 May to 3 Aug. 1945; J. Colman leg.; upper intertidal; NHMUK 1950.1.5.72-95.

\section{Paratypes}

ST HELENA • several atokous; same collection data as for holotype; NHMUK 1950.1.5.72-95b.

\section{Comparative material}

Syntypes of Neanthes indica brunnea (Day, 1957)

MOZAMBIQUE • 1 atokous; Inhambane, Morrumbene Estuary; J.H. Day leg.; NHMUK 1961.16.23 • 1 atokous; same collection data as for preceding; SAM-A-20983.

\section{Description}

Colour AND MEASUREMENTS. Syntype atokous, complete but fragmented into two parts, in poor condition, $26.5 \mathrm{~mm}$ TL, $3.3 \mathrm{~mm} \mathrm{L15,} 1 \mathrm{~mm}$ W15, with 89 chaetigers. Body pale yellow, lacking pigmentation patterns, stained with Shirlastain A to observe edges, scars and paragnaths (Fig. 3A-D).

Prostomium. Campanulate, as long as wide (Fig. 3B); anterior end broad, distally complete; anterolateral gap beside palpophore narrow, as wide as antennal diameter; dorsal groove distinct, shallow, running mid-subdistally. Nuchal organs exposed, broad, twice as wide as diameter of posterior pair of eyes.

PalPophoRes. Sub-conical, 1.2 times wider than long (Fig. 3B), as long as four-fifths of entire prostomium; with distinct sub-distal transverse groove. Palpostyles ovoid, thick, with diameter as wide as two-fifths of palpophore.

AnTEnNAE. Tapered, thick, long, extending forwards beyond tip of palpophore and posteriorly to halflength of prostomium; antennae separated, with gap as wide as basal diameter of antennae (Fig. 3B).

EYES. Paired eyes purplish but gradually fading, arranged in a trapezoid form; gap between both pairs two-thirds as wide as diameter of posterior pair of eyes (Fig. 3B); anterior pair of eyes oval, 1.6 times as wide as basal diameter of antennae, gap between both eyes 3.5 times as wide as diameter of eyes, with lens barely distinct, translucent, covering $20 \%$ of eye; posterior pair of eyes rounded, 1.7 times as wide as basal diameter of antennae, with lens distinct, translucent, placed in middle of eye and covering $20 \%$ of it.

Apodous anterior SEgment. Segment 4 times wider than long, 1.5 times as long as chaetiger 1, with rounded anterior margin and ventrolateral projections; dorsum without marked transverse wrinkle.

TENTACULAR CIRRI. Cirri of right flank dehiscent, remaining slightly thickened, smooth (Fig. 3B); posterodorsal cirri broken, extending posteriorly to chaetiger 6 , but according to original description, extending to chaetiger 10; antero-dorsal cirri broken, extending posteriorly to chaetiger 3; postero-ventral cirri extended over opposite side of prostomium; antero-ventral cirri slightly longer than postero-ventral cirri and extending beyond twice length of palpophore; dorsal cirrophores cylindrical, ventral cirrophores ring-shaped, postero-dorsal cirrophores 1.5 times as long as antero-dorsal cirrophores, antero-ventral cirrophores 1.2 times as wide as postero-ventral cirrophores. 
PharynX. Everted, in poor condition, damaged, jaws and several areas missing, only areas V and VI remain. Pharynx of second syntype described here, everted, in poor condition, damaged, jaws missing; paragnaths on maxillary and oral rings amber, barely distinct but stained here (Fig. 3C-D), consisting of conical, p-bars, and merged paragnaths; plate-like basements absent. Area I: 1, small cone; areas IIa: 31 and IIb: 38, three slightly regular rows of uneven cones in eyebrow-shaped patch, subdistal cones larger, fang-shaped in outer-most row (Fig. 3C); area III: 18, four irregular rows of uneven cones in sub-oval patch, with three distinct laterally-isolated cones, distal cones smaller; areas IVa: missing and IVb: 26, L-shaped patch with proximal half consisting of two regular rows and distal half with four slightly regular rows of uneven cones and four long and slender merged paragnaths (3-4 times longer than wide) located near jaw; area V: 1 (1), small conical paragnath placed on same level between most distal and proximal paragnaths on area VI (Fig. 3C); areas VIa: 7 (5) and VIb: 6 (5), oblique transverse row of uneven p-bars becoming shorter outwards (six in VIa, four in VIb; Fig. 3C) and one single outermost cone (Fig. 3C); areas VII-VIII: 31, two bands of cones, with anterior band consisting of two transversely aligned rows (furrow row with one small cone and ridge row with one fang-shaped cone on each region) (Fig. 3D), and posterior band with two transverse rows (Fig. 3D). Areas VI-V-VI ridge pattern, $\pi$-shaped. Gap between area VI and areas VII-VIII narrow, as wide as palpostyle.

Paired oesophageal caeca. Unknown.

PARAPODIA. Without glandular, dorsal patches. Notopodia consisting of dorsal cirrus, dorsal ligule (distal and proximal), notopodial prechaetal lobe, and median ligule in biramous parapodia. Neuropodia consisting of neuroacicular ligule with inferior and postchaetal lobes, ventral ligule, and ventral cirrus; superior lobe absent throughout.

Dorsal CIRRI. Cirriform, long, extending markedly beyond distal region of dorsal ligule throughout (Fig. 3E-I); dorsal cirri 3-3.5 times as long as proximal region of dorsal ligule in anteriormost and anterior parapodia (Fig. 3E-F), 2-2.5 times as long as that in following parapodia (Fig. 3G-I); attached basally to dorsal ligule in anteriormost parapodia (Fig. 3E), medially in anterior, middle and posterior parapodia (Fig. 3F-I), two-thirds in posteriormost parapodia.

Dorsal Ligule. Proximal region even throughout, except slightly humped from middle parapodia towards posterior end; shorter than distal region of dorsal ligule in anteriormost parapodia (Fig. 3E), as long as that in anterior, middle and posterior parapodia (Fig. 3F-I), 1.5 times as long as that in posteriormost parapodia; two irregular glandular patches covering partially proximal region of dorsal ligule in anteriormost and anterior parapodia (Fig. 3E-F) and entirely covering that in following parapodia (Fig. 3G-I). Distal region well developed, becoming slightly longer towards posterior end; digitiform in anteriormost parapodia (Fig. 3E), bluntly rounded in anterior parapodia (Fig. 3F), conical in middle parapodia (Fig. 3G-H), bluntly conical in remaining parapodia (Fig. 3I); as long as or slightly shorter than median ligule in anterior parapodia (Fig. 3F), longer than that in following parapodia; projecting beyond notoacicula throughout; one irregular glandular patch covering entirely distal region of dorsal ligule (Fig. 3F-I).

Notopodial prechaetal lobe. Present from parapodia 5 to parapodia 14 (Fig. 3F); bluntly rounded, as long as median ligule in anterior parapodia, then reducing and tapering gradually to notoacicular process that disappears in about parapodia 32 .

Median Ligule. Digitiform in anteriormost parapodia, bluntly rounded in anterior parapodia (Fig. 3F), conical in middle parapodia (Fig. 3G-H), bluntly conical in following parapodia (Fig. 3I), becoming narrower from middle parapodia towards posterior end. 

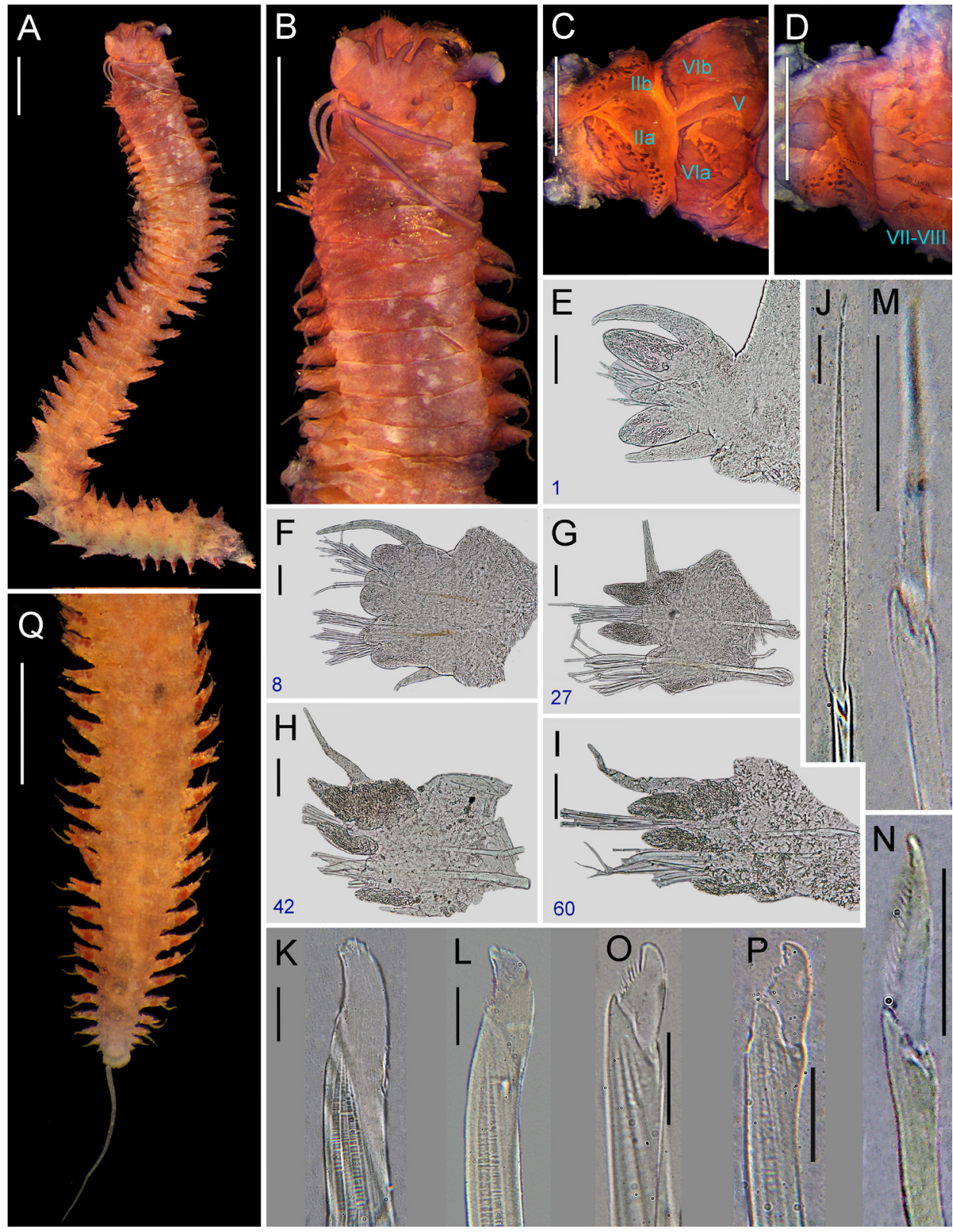

Fig. 3. Neanthes helenae Kinberg, 1865. A-B, E-Q. Complete syntype (SMNH Type-457) from Jamestown, St Helena Island, atokous. C-D. Incomplete syntype (SMNH Type-457) from Jamestown, St Helena Island, atokous. A. Entire body in dorsal view. B. Anterior end in dorsal view. C. Everted pharynx in dorsal view. D. Everted pharynx in ventral view. E. Right parapodium from chaetiger 1 in anterior view with ventral cirri missing. F. Right parapodium from chaetiger 8 in anterior view. G. Right parapodium from chaetiger 27 in anterior view. H. Right parapodium from chaetiger 42 in anterior view with ventral cirri missing. I. Right parapodium from chaetiger 60 in anterior view. J. Homogomph spiniger from notochaetae (chaetiger 27). K. Heterogomph spiniger from subacicular neurochaetae (chaetiger 1). L. Heterogomph falciger from subacicular neurochaetae (chaetiger 1). M. Heterogomph, fused falciger from supracicular neurochaetae (chaetiger 42). N. Heterogomph falciger from supracicular neurochaetae (chaetiger 60). O. Heterogomph falciger from subacicular neurochaetae (chaetiger 13). P. Heterogomph falciger from subacicular neurochaetae (chaetiger 60). Q. Posterior end in dorsal view. A-D, Q: stained with Shirlastain A. Roman numerals refer to the areas and Arabic numbers to chaetigers. Scale bars: A-B $=1 \mathrm{~mm}$; C-D, Q $=0.5 \mathrm{~mm}$; $\mathrm{E}-\mathrm{I}=0.1 \mathrm{~mm}$; J-P $=20 \mu \mathrm{m}$. 
Neuroacicular ligule. Smaller than ventral ligule in anteriormost parapodia (Fig. 3E), as long as in following parapodia (Fig. 3F-I), 1.5-2 times as wide as ventral ligule throughout.

NeUROPOdIAL INFERIOR LOBE. Slightly developed and longer than neuroacicular ligule in first four parapodia, absent in following chaetigers.

Neuropodial postchaetal lobe. Digitiform, longer than neuroacicular ligule in first 5 parapodia (Fig. 3E), then reducing gradually to disappear in parapodium 12.

Ventral Ligule. Well developed throughout; digitiform, thick in anteriormost parapodia (Fig. 3E), bluntly rounded, thick in anterior parapodia (Fig. 3F), digitiform in following chaetigers; smaller than median ligule throughout, more distinct in middle and posterior parapodia (Fig. $3 \mathrm{H}-\mathrm{I}$ ); shorter than distal region of dorsal ligule in parapodia 1 and 2 (Fig. 3E).

VentRAL CIRRI. Cirriform, slender; as long as ventral ligule in anteriormost parapodia (Fig. 3E), twothirds as long as that in following parapodia (Fig. 3F, H).

ACICUlAE. Colour mostly faded by long-term preservation. Notoaciculae absent in first two chaetigers (Fig. 3E). Neuroaciculae extending similarly to distal end of notoaciculae throughout, with proximal half $1.3-1.5$ times as wide as notoaciculae.

NotochaEtAE. All homogomph spinigers (Fig. 3J); 10-13 spinigers present in anterior parapodia, 6-9 spinigers in middle parapodia, 4-5 spinigers in posterior parapodia and 3 spinigers in posteriormost parapodia.

SuPRACicular NeURochaEtae. Consisting of homogomph spinigers and heterogomph falcigers (Fig. 3KL), both present throughout; 4-5 spinigers present in anteriormost parapodia, 6-7 spinigers in anterior parapodia, 4-5 spinigers in middle parapodia, 1-2 spinigers in posterior and posteriormost parapodia; 2 falcigers present in anteriormost parapodia, 2-3 falcigers in anterior parapodia, 1-2 falcigers in middle parapodia, 1 falciger in posterior and posteriormost parapodia.

Subacicular neurochaetae. Consisting of heterogomph spinigers (Fig. 3M) and heterogomph falcigers (Fig. 3N-P), both present throughout; 3 spinigers present throughout, sometimes 4 spinigers in middle parapodia; 8 falcigers present in anteriormost parapodia, $8-12$ falcigers in anterior parapodia, 3-6 falcigers in middle parapodia, 1-3 falcigers in posterior and posteriormost parapodia.

BlADEs. Both homogomph (Fig. 3J) and heterogomph (Fig. 3M) spinigers with blades of medium and long size (B/A ratio 6.6-11.2), finely serrated towards toothed edge, evenly spaced, except homogomph spinigers from middle parapodia towards posterior end with coarse proximal teeth. Blades of heterogomph falcigers in anteriormost parapodia slender, convex, long ( $B / A$ ratio $2.2-2.7)$, terminal tooth blunt with inconspicuous tendon (Fig. $3 \mathrm{~N}$ ), serrations present in about two-fifths $(0.60-0.65)$ of total blade length; blades in following parapodia thicker, convex, short $(B / A$ ratio $0.9-1.6)$, terminal tooth incurved with distinct tendon in supracicular fascicle (Fig. 3K-L), blunt with inconspicuous tendon in subacicular fascicle (Fig. 3O-P), serrations present in about one-fifth to one-quarter (0.22-0.28) of total blade length. Shaft of supracicular falcigers thicker than subacicular ones in middle and posterior parapodia; camerated, with cavity divided sub-distally into two longitudinal partitions, supracicular rarely divided into three. Fused heterogomph falcigers present in supracicular fascicle, fusing from parapodia 23, simple in parapodia 35 to parapodia 65 , separating gradually to non-fused in posteriormost parapodia.

PyGidium. Distinctly projected, bluntly rounded, wider than long (Fig. 3Q), with anal cirri as long as last 11 chaetigers; cirrophores of anal cirri barely developed. 


\section{Description of holotype and two paratypes of Nereis (Neanthes) nanciae}

Colour AND MEASUREMENTS. All complete atokous (one paratype female), in good condition, 20-22.5 mm TL, 6.3-7.6 mm L15, 1-1.6 mm W15, with 60-64 chaetigers. Body brownish, distal half of prostomium, apodous anterior segment and few anterior chaetigers with reddish-brown pigmentation (Fig. 4A-B), smallest specimen forming faint X-shaped pattern on dorsum of anterior segments.

Prostomium. Campanulate, as long as wide or slightly longer than wide (Fig. 4B); anterior end broad, distally complete; anterolateral gap beside palpophore narrow, as wide as antennal diameter; dorsal groove distinct, shallow, running mid-subdistally. Nuchal organs deeply embedded, broad, 1.7-2 times as wide as diameter of posterior pair of eyes.

Palpophores. Sub-conical, as wide as long to slightly wider as long (Fig. 4B), subequal to entire length of prostomium; with distinct sub-distal transverse groove. Palpostyles ovoid, thick, with diameter as wide as two-fifths to half of palpophore.

AnTENNAE. Tapered, thick, long, extending forwards beyond tip of palpophore and posteriorly to half to two-fifths length of prostomium; antennae separated, with gap subequal to three-quarters as wide as basal diameter of antennae (Fig. 4B).

EYES. Paired eyes black, arranged in a trapezoid form; gap between both pairs one-quarter to threequarters as wide as diameter of posterior pair of eyes (Fig. 4B); anterior pair of eyes oval to rounded, 1.5-1.7 times as wide as basal diameter of antennae, gap between both eyes 3-3.5 times as wide as diameter of eyes, with lens barely distinct, translucent, covering $10-20 \%$ of eye; posterior pair of eyes rounded, 1.2-1.5 times as wide as basal diameter of antennae, with lens distinct, translucent, placed in middle of eye and covering $15-25 \%$ of it.

Apodous ANTERIOR SEgment. Segment 3.5-4 times wider than long, 1.5 times as long as chaetiger 1, with rounded anterior margin and distinct ventrolateral projections (Fig. 4C-D); dorsum without marked transverse wrinkle.

TENTACULAR CIRRI. Thick, smooth (Fig. 4B); postero-dorsal cirri extending posteriorly to chaetiger 7-8; antero-dorsal cirri extending posteriorly to chaetiger 3; postero-ventral cirri extended over opposite side of prostomium; antero-ventral cirri subequal or slightly longer than postero-ventral cirri and extending beyond 1.5-2 times length of palpophore; dorsal cirrophores cylindrical, ventral cirrophores ring-shaped, postero-dorsal cirrophores 1.5 times as long as antero-dorsal cirrophores, antero-ventral cirrophores subequal or slightly wider than postero-ventral cirrophores.

PharYnx. Non-everted. Jaws with distal quarter brownish, remaining yellow amber, with 9-10 welldeveloped and sharp denticles (Fig. 4E); pulp cavity with two canals (Fig. 4F). Reddish-brown paragnaths on maxillary and oral rings (Fig. $4 \mathrm{G}-\mathrm{H}$ ), consisting of cones, p-bars, and merged paragnaths; plate-like basements absent. Area I: 1-2, cones; areas IIa: 20-27 and IIb: 19-27, two slightly regular rows of uneven cones in eyebrow-shaped patch, subdistal cones larger, fang-shaped in outer-most row (Fig. 4G); area III: $18-28$, two to four irregular rows of uneven cones in sub-oval or sub-rectangular patch, with two to four distinct laterally-isolated cones, distal cones smaller; areas IVa: 24-45 and IVb: 26-48, L-shaped patch (Fig. 4G) with proximal half consisting of two regular rows and distal half with three or four slightly regular rows of uneven cones and four to six long and slender (3-4 times longer than wide) merged paragnaths located near jaw; area V: 1 (1), coarse conical paragnath placed slightly behind level of paragnaths on area VI (Fig. 4G); areas VIa: 5-8 and VIb: 5-7, oblique transverse row of uneven p-bars becoming shorter outwards (four to seven in VIa, four to six in VIb; Fig. 4H) and one single outermost cone (Fig. 4H); areas VII-VIII: 28-33, two bands of cones ventrally well separated, with 
anterior band consisting of two transversely aligned rows (furrow and ridge rows with one coarse cone on each region), and posterior band with two transverse slightly displaced rows (Fig. 4G). Areas VI-VVI ridge pattern, $\pi$-shaped. Gap between area VI and areas VII-VIII narrow, as wide as palpostyle.

Paired oesophageal caeca. Present.

PARAPODIA. Without glandular, dorsal patches. Notopodia consisting of dorsal cirrus, dorsal ligule (distal and proximal), notopodial prechaetal lobe, and median ligule in biramous parapodia. Neuropodia consisting of neuroacicular ligule with inferior and postchaetal lobes, ventral ligule, and ventral cirrus; superior lobe absent throughout.

DORSAL CIRRI. Cirriform, long, extending markedly beyond distal region of dorsal ligule throughout (Fig. 4I-M); dorsal cirri 3-3.5 times as long as proximal region of dorsal ligule in anteriormost and anterior parapodia (Fig. 4I-J), 2-2.5 times as long as that in following parapodia (Fig. 4K-M); attached basally to dorsal ligule in anteriormost parapodia (Fig. 4I), medially in anterior, middle and posterior parapodia (Fig. 4J-L), two-thirds in posteriormost parapodia (Fig. 4M).

Dorsal Ligule. Proximal region even towards posterior end, except slightly humped from middle parapodia towards posterior end; shorter than distal region of dorsal ligule in anteriormost parapodia (Fig. 4I), as long as that in anterior, middle and posterior parapodia (Fig. 4J-L), 1.5 times as long as that in posteriormost parapodia (Fig. 4M); two irregular glandular patches covering partially proximal region of dorsal ligule in anteriormost parapodia (Fig. 4I) and entirely covering that in following parapodia (Fig. 4J-M). Distal region well developed, becoming slightly longer towards posterior end; digitiform in anteriormost parapodia (Fig. 4I), bluntly rounded in anterior parapodia (Fig. 4J), conical to bluntly conical in following parapodia (Fig. $4 \mathrm{~K}-\mathrm{M}$ ); as long as or slightly shorter than median ligule in anterior and middle parapodia (Fig. 4J-L), longer than that in following parapodia; projecting beyond notoacicula throughout; one irregular glandular patch covering entirely distal region of dorsal ligule.

Notopodial prechaetal lobe. Present from parapodia 5 to parapodia 14-16 (Fig. 4J); bluntly rounded, as long as median ligule in anterior parapodia, then reducing and tapering gradually to notoacicular process that disappears in about parapodia 34-37.

Median Ligule. Digitiform in anteriormost parapodia, bluntly rounded in anterior parapodia (Fig. 4J), digitiform to bluntly conical in following parapodia (Fig. 4K-M), becoming narrower from middle parapodia towards posterior end.

Neuroacicular ligule. Smaller than ventral ligule in anteriormost and posteriormost parapodia (Fig. 4I, $\mathrm{M}$ ), as long as in remaining parapodia (Fig. $4 \mathrm{~J}-\mathrm{L}$ ), parapodia $1.5-2$ times as wide as ventral ligule throughout.

NeUROPODIAL INFERIOR LOBE. Slightly developed and longer than neuroacicular ligule in first four or five parapodia, absent in following chaetigers.

Neuropodial postchaetal lobe. Digitiform, longer than neuroacicular ligule in first 5 parapodia (Fig. 4I), then reducing gradually to disappear in parapodia $10-12$.

Ventral Ligule. Well developed throughout; digitiform, thick in all parapodia, except bluntly rounded, thick in anterior parapodia (Fig. $4 \mathrm{~J}$ ); smaller than median ligule throughout, more distinct from middle parapodia towards posterior end (Fig. 4L-M); shorter than distal region of dorsal ligule in parapodia 1 and 2 (Fig. 4I). 
Ventral CIRRI. Cirriform, slender; as long as ventral ligule in anteriormost parapodia (Fig. 4I), twothirds to three-quarters as long as that in following parapodia (Fig. 4J-M).

ACICUlAe. Mostly black with basal end uncoloured in anterior chaetigers, one-half paler in posterior chaetigers (Fig. 4L). Notoaciculae absent in first two chaetigers (Fig. 4I). Neuroaciculae extending similarly to distal end of notoaciculae throughout, with proximal half $1.3-1.5$ times as wide as notoaciculae.

NotochaEtAe. All homogomph spinigers; $11-14$ spinigers present in anterior parapodia, 7-9 spinigers in middle parapodia, $4-5$ spinigers in posterior parapodia and 2-3 spinigers in posteriormost parapodia.

Supracicular neurochaetae. Consisting of homogomph spinigers and heterogomph falcigers (Fig. 4N), both present throughout; 3-5 spinigers present in anteriormost parapodia, 5-7 spinigers in anterior parapodia, 3-5 spinigers in middle parapodia, 1-2 spinigers in posterior and posteriormost parapodia; 2 falcigers present in anteriormost parapodia, $1-3$ falcigers in anterior and middle parapodia, 1 falciger in posterior and posteriormost parapodia.

Subacicular neurochaetae. Consisting of heterogomph spinigers and heterogomph falcigers (Fig. 4OP), both present throughout; 2-3 spinigers present throughout, except 1 spiniger in posteriormost parapodia; 5-6 falcigers present in anteriormost parapodia, 7-10 falcigers in anterior parapodia, 5-6 falcigers in middle parapodia, 4 falcigers in posterior parapodia, $2-3$ falcigers in posteriormost parapodia.

BLADES. Both homogomph and heterogomph spinigers with blades of medium and long size (B/A ratio 5.1-8.3), finely serrated towards toothed edge, evenly spaced, except homogomph spinigers from middle parapodia towards posterior end with coarse proximal teeth. Blades of heterogomph falcigers in anteriormost parapodia slender, convex, long ( $B / A$ ratio 2.3-3.4), terminal tooth blunt with inconspicuous tendon (Fig. 4O), serrations present in about half to two-thirds (0.52-0.66) of total blade length; blades in following parapodia thicker, convex, short ( $B / A$ ratio $0.65-1.3)$, terminal tooth incurved with distinct tendon in supracicular fascicle (Fig. 4P), blunt with inconspicuous tendon in subacicular fascicle, serrations present in about one-sixth to one-third (0.16-0.38) of total blade length. Shaft of supracicular falcigers thicker than subacicular ones in middle and posterior parapodia; camerated, with cavity divided sub-distally into two longitudinal partitions. Fused heterogomph falcigers present in supracicular fascicle (Fig. 4N), fusing from parapodia 23-26, simple in parapodia 34-35 to parapodia $59-65$, separating gradually to non-fused in posteriormost parapodia.

PyGiDium. Distinctly projected, bluntly rounded, as wide as long (Fig. 4Q), with anal cirri as long as last 11-12 chaetigers; cirrophores of anal cirri barely developed.

\section{Remarks}

Neanthes helenae was not compared in the original description by Kinberg (1865), although he placed it within a group formed by two other species, N. rigida (Grube \& Ørsted in Grube, 1858) and N. vallata (Grube \& Kröyer in Grube, 1858), currently belonging to Nereis and Perinereis (Salazar-Vallejo \& Eibye-Jacobsen 2012), respectively. Among all species of Neanthes, N. helenae from St Helena Island resembles N. flava Wu, Sun \& Yang, 1981, N. indica brunnea, N. nubila (Savigny, 1822) likely from the North Atlantic (precise locality unknown), and N. talehsapensis (Fauvel, 1932) from the Gulf of Thailand. These species share proximal region of dorsal ligules of similar size throughout the body (or slightly enlarged in posterior parapodia), presence of neuropodial postchaetal and notopodial prechaetal lobes at least in some anterior chaetigers, absence of neuropodial superior lobes, areas VII-VIII with two well-defined bands of more than 20 paragnaths, and area I with no more than two paragnaths (see Villalobos-Guerrero \& Idris 2021: table 2). 


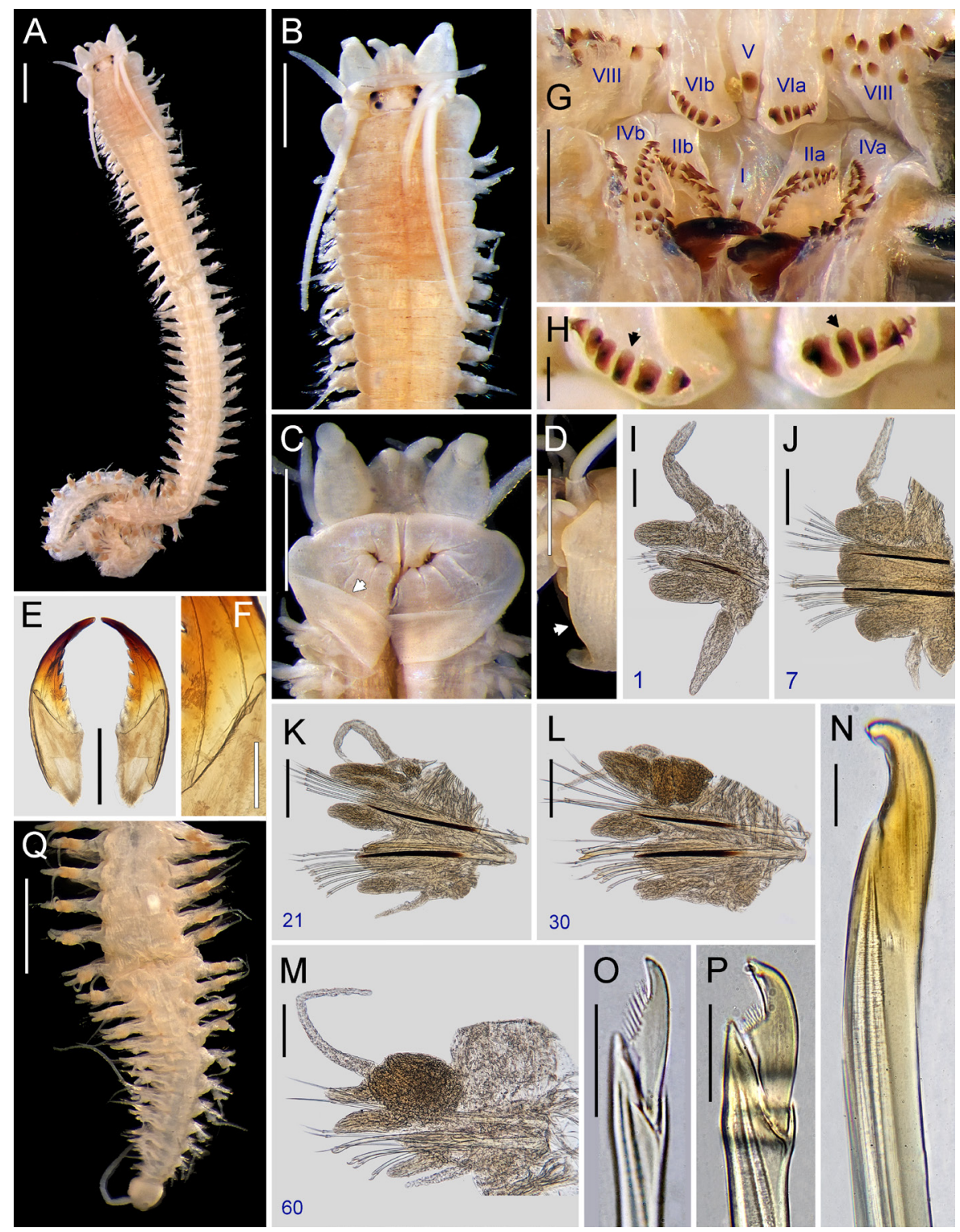

Fig. 4. Neanthes helenae Kinberg, 1865. A-C, I-P. Holotype of Nereis (Neanthes) nanciae Day, 1949 (NHMUK 1950.1.5.72-95) from Jamestown, St Helena Island, atokous. A. Entire body in dorsal view. B. Anterior end in dorsal view. C. Anterior region in ventral view, arrow indicates ventrolateral projection. I. Left parapodium from chaetiger 1 in posterior view. J. Left parapodium from chaetiger 7 in posterior view. K. Right parapodium from chaetiger 21 in anterior view. L. Left parapodium from chaetiger 30 in posterior view with ventral cirri contracted and hidden behind the neuroacicular ligule. M. Right parapodium from chaetiger 60 in anterior view. N. Heterogomph fused falciger from supracicular neurochaetae (chaetiger 30). O. Heterogomph falciger from subacicular neurochaetae (chaetiger 7). P. Heterogomph falciger from subacicular neurochaetae (chaetiger 30). - D-H, Q. Paratype of Nereis (Neanthes) nanciae Day, 1949 (NHMUK 1950.1.5.72-95) from Jamestown, St Helena Island, atokous. D. Anterior region in lateral view, arrow indicates ventrolateral projection. E. Left jaw in dorsal and ventral views, respectively. F. Inner canals of jaws in ventral view. G. Non-everted pharynx in ventral view. H. Area VI of oral ring of non-everted pharynx in ventral view, arrows indicate p-bars. Q. Posterior end in dorsal view. Roman numerals refer to the areas and Arabic numbers to chaetigers. Scale bars: A-C, Q $=1 \mathrm{~mm}$; D-E, G $=0.5 \mathrm{~mm} ; \mathrm{F}, \mathrm{J}-\mathrm{L}=0.2 \mathrm{~mm}$; H-I, $\mathrm{M}=0.1 \mathrm{~mm}$; N-P $=20 \mu \mathrm{m}$. 
Moreover, $N$. helenae is distinguishable from them all by the following diagnostic features: (I) the presence of p-bars on area VI, in contrast to its absence in those species; (II) the presence of ventrolateral projections on the apodous segment, in comparison to its absence in those species; (III) the presence of simple chaetae (fused falcigers) in supracicular fascicle, in contrast to its absence in $N$. flava, $N$. indica brunnea, $N$. nubila and N. talehsapensis; (IV) one paragnath on area V, in comparison to none in $N$. flava, $N$. indica brunnea, $N$. nubila and $N$. talehsapensis; (V) the paragnaths disposed in a transverse row on area VI, in contrast to those in a rounded or oval patch in N. flava, N. indica brunnea and N. nubila, and a cross or irregular patch in $N$. talehsapensis; (VI) the dorsal cirri extending markedly beyond distal region of dorsal ligule at least in anterior parapodia, in comparison to those that are subequal to or not extending beyond end in N. flava, N. indica brunnea and N. nubila; (VII) 18-28 paragnaths on area III, in contrast to one in $N$. flava and 5-9 in N. indica brunnea; (VIII) the heterogomph falciger blade with hammerheaded terminal tooth and distinct tendon in middle and posterior parapodia, in comparison to those with blunt terminal tooth and inconspicuous tendon in N. flava and N. talehsapensis; (IX) the presence of merged paragnaths, in contrast to their absence in N. flava and N. indica brunnea; (X) the antennae well separated from each other, in comparison to those that are closely together in $N$. flava and $N$. indica brunnea; (XI) the campanulate prostomium, in contrast to an ovoid shape in $N$. indica brunnea and $N$. nubila; (XII) the $\pi$-shaped ridge pattern of areas VI-V-VI, in comparison to that $\lambda$-shaped pattern in $N$. indica brunnea; (XIII) the dorsum of segments with pigmentation bands, in contrast to a pigment band present only in the apodous segment in $N$. indica brunnea; (XIV) the paragnaths present on both ridges and furrows of areas VII-VIII of the pharynx, in contrast to those only present on ridges in N. nubila; and (XV) the aciculae mostly black, in comparison to those rather pale colour in $N$. talehsapensis.

Neanthes helenae was described without illustrations by Kinberg (1865) using an unknown number of specimens collected near St Helena Island. The type material was not addressed in the literature, and most of its morphology remained unknown until this study. The two syntypes are in poor condition, but the relevant diagnostic features are still visible, and thus are useful to define the species' morphology.

Day (1949) described Nereis (Neanthes) nanciae from St Helena Island with several atoke specimens, but he did not justify the proposal as a new species. Later, Hartman (1959) transferred the species to Neanthes and suggested it as a possible synonym of the incompletely known N. helenae. Fauchald (1972) considered Neanthes nanciae as a valid species, but Wilson (1984) agreed with Hartman's assumptions, suggesting $N$. nanciae as a possible junior synonym of $N$. helenae. After the detailed examination of both species' type material, $N$. helenae is here regarded as the senior synonym of $N$. nanciae as a result of the overlap in unique and diagnostic features among other species in Neanthes, such as the presence of p-bar paragnaths on area VI, ventrolateral projections on the apodous segment and the presence of simple chaetae (fused falcigers) in supracicular fascicle.

\section{Distribution}

Saint Helena Island.

\section{Ecology}

The upper part of the intertidal zone to $73 \mathrm{~m}$ depth (Day 1949).

\section{Reproduction}

Unknown.

Neanthes mossambica (Day, 1957)

Fig. 5

Nereis (Neanthes) mossambica Day, 1957: 78-80, text-fig. 3e- $\mathrm{h}, \mathrm{j}-\mathrm{k}$ [type locality: Morrumbene Estuary, Mozambique]. 
Nereis (Neanthes) mossambica - Hartman 1959: 265. — Day 1967: 318-320, fig. 14.8.g-k.

Neanthes mossambica - Fauchald 1972: 409 (group IIB 2b). — Wilson 1984: 226 (group IIB 2b) (all previous in species list). - Villalobos-Guerrero \& Idris 2021: 560 (table 1), 562 (table 2).

Nereis mossambica - Day 1974: 73 (table 5), 87 (habitat).

\section{Type material}

Holotype

MOZAMBIQUE • atokous $\$$; Inhambane, Morrumbene Estuary; NHMUK 1961.16.22.

\section{Paratype}

MOZAMBIQUE • 1 atokous; same collection data as for holotype; SAM-A-20984.

\section{Comparative material}

Syntypes de Neanthes indica brunnea (Day, 1957)

MOZAMBIQUE • 2 atokous; Inhambane, Morrumbene Estuary; J.H. Day leg.; NHMUK 1961.16.23 • 1 atokous; same collection data as for preceding; SAM-A-20983.

\section{Description}

Colour and MEASUREMENTS. Holotype atokous female, complete but with regenerating posterior end, in good condition, 32 (12) mm TL, 8 (4) mm L15, 1.3 (1) mm W15, with 68 (47) chaetigers. Body colour yellowish, with brownish pigmentation in dorsum of prostomium, palps, and present throughout in dorsum of anterior segments (Fig. 5A-B).

Prostomium. Campanulate, 1.4 times longer than wide (Fig. 5B); anterior end broad, distally complete; anterolateral gap beside palpophore broad, 1.5 times as wide as antennal diameter; dorsal groove distinct, shallow, running through distal three-quarters of prostomium. Nuchal organs deeply embedded, medium size, subequal to diameter of posterior pair of eyes.

Palpophores. Sub-conical, longer than wide, as long as four-fifths of entire prostomium (Fig. 5A); with distinct sub-distal transverse groove. Palpostyles ovoid, thin, with diameter as wide as one-fifth of palpophore.

ANTENNAE. Tapered, slender, long, extending forwards slightly beyond end of palpophore and posteriorly to half-length of prostomium; antennae well separated, with gap as wide as basal diameter of antennae.

EYES. Paired eyes blackish, arranged in a trapezoid form (Fig. 5B); gap between both pairs one-third as wide as diameter of posterior pair of eyes; anterior pair of eyes sub-rounded, 1.2 times as wide as basal diameter of antennae, gap between both eyes 3.5 times as wide as diameter of eyes, with lens slightly distinct, whitish, covering $10 \%$ of eye; posterior pair of eyes rounded, as wide as basal diameter of antennae, with lens barely distinct, dark, placed in middle of eye and covering $15 \%$ of it.

Apodous anterior Segment. Segment 3.5 times wider than long, 1.4 times as long as chaetiger 1, with rounded anterior margin (Fig. 5B), dorsum without marked transverse wrinkle.

Tentacular CIRRI. Slender, smooth (Fig. 5B); postero-dorsal cirri extending posteriorly to chaetiger 8 (4), twice as long as antero-dorsal cirri; antero-dorsal cirri extending posteriorly to chaetiger 4 (2); postero-ventral cirri extended over opposite side of prostomium; antero-ventral cirri nearly as long as postero-ventral cirri and extending slightly beyond palpophore; dorsal cirrophores cylindrical, ventral cirrophores ring-shaped, postero-dorsal cirrophores 1.5 times as long as antero-dorsal cirrophores, antero-ventral cirrophores 1.5 times as wide as postero-ventral cirrophores. 
Pharynx. Non-everted, previously dissected. Jaws reddish in distal quarter, remaining amber, with 8 (5) blunt, wear denticles; pulp cavity with two canals. Brownish conical paragnaths on maxillary and oral rings (Fig. 5C), except reddish in areas VII-VIII; merged paragnaths and plate-like basements absent. Area I: 6 (2), triangular patch of uneven cones, single distal cone smaller; areas IIa: 15 (15) and IIb: 15 (17), three irregular rows of uneven cones in sub-triangular patch, cones in outer-most row larger (Fig. 5C); area III: 32 (23), four slightly regular rows of uneven cones in rectangular patch, without distinct laterally-isolated cones, distal cones smaller (Fig. 5C); areas IVa: 31 (25) and IVb: 32 (24), bow-shaped patch with proximal half consisting of four irregular rows and distal half with three irregular rows of uneven cones (Fig. 5C); area V: 0 (0) (Fig. 5C); areas VIa: 1 (1) and VIb: 1 (1), coarse cone, distally wear in VIa (Fig. 5C-D); areas VII-VIII: 50 (42), two well-separated bands of cones, with anterior band consisting of two transversely slightly displaced rows of coarse cones (furrow row and ridge row with one cone on each region) (Fig. 5C), and posterior band with three transverse rows slightly displaced from each other (furrow row middle with one cone on each region, distal ridge row with two or three coarse cones on each region, proximal ridge row with one small cone on each region) (Fig. 5C). Areas VI-V-VI ridge pattern, $\lambda$-shaped. Gap between area VI and areas VII-VIII narrow, as wide as distal end of palpophore.

\section{Paired oesophageal caeca. Absent.}

PARAPODIA. Without glandular, dorsal patches. Notopodia consisting of dorsal cirrus, dorsal ligule (distal and proximal), notopodial prechaetal lobe, and median ligule in biramous parapodia. Neuropodia consisting of neuroacicular ligule with inferior and postchaetal lobes, ventral ligule, and ventral cirrus; superior lobe absent throughout.

Dorsal CIRRI. Cirriform, long, extending markedly beyond distal region of dorsal ligule throughout (Fig. 5E-I); dorsal cirri 5-5.5 times as long as proximal region of dorsal ligule in anteriormost and anterior parapodia (Fig. 5E-F), 3-4 times as long as that in middle parapodia (Fig. 5G-H), 2-2.5 times as long as that in posterior parapodia (Fig. 5I); attached basally to dorsal ligule in anteriormost parapodia (Fig. 5E), one-third in anterior parapodia (Fig. 5F), medially in following parapodia (Fig. 5G-I).

Dorsal Ligule. Proximal region even towards posterior end (Fig. 5E-I); shorter than distal region of dorsal ligule in anteriormost and anterior parapodia (Fig. 5E-F), as long as that in following parapodia (Fig. 5G-I); glandular patches absent. Distal region well developed with similar length throughout (Fig. 5E-I); subulate, slender, as long as median ligule in anterior parapodia, conical and smaller than that in following parapodia; projecting beyond notoacicula throughout; glandular patches absent.

Notopodial PRechaetal lobe. Present from parapodia 5 to parapodia 18 ; bluntly conical, half as long as median ligule in anterior parapodia (Fig. $5 \mathrm{~F}$ ), then reducing and tapering gradually to notoacicular process that disappears in about parapodia 36 (Fig. $5 \mathrm{H}-\mathrm{I}$ ).

Median Ligule. Subulate, slender in anterior parapodia (Fig. 5E-F), conical in following parapodia (Fig. 5G-I), becoming slightly longer from middle parapodia towards posterior end.

Neuroacicular ligule. Smaller than ventral ligule in anteriormost parapodia (Fig. 5E), as long as in following parapodia (Fig. 5F-I), twice as wide as ventral ligule throughout.

NeUROPODIAL INFERIOR LOBE. Slightly developed and longer than neuroacicular ligule in first 14 parapodia (Fig. 5E-F), absent in following chaetigers. 
Neuropodial postchaetal lobe. Present throughout; bluntly conical, except conical in posterior parapodia; as long as neuroacicular ligule in anteriormost parapodia (Fig. 5E), smaller than that in following parapodia (Fig. 5F-I).

Ventral Ligule. Well-developed and conical throughout (Fig. 5E-I); smaller than median ligule throughout, more distinct in posterior parapodia (Fig. 5I); extending beyond distal region of dorsal ligule in parapodia 1 and 2 (Fig. 5E).

Ventral CIRRI. Cirriform, slender; two-thirds as long as ventral ligule in anteriormost and anterior parapodia (Fig. 5E-F), one-third as long as that in middle parapodia, levelling base of that in posterior parapodia.

Aciculae. Black, with basal end uncoloured. Notoaciculae absent in first two chaetigers (Fig. 5E). Neuroaciculae extending beyond distal end of notoaciculae throughout, more distinct in anteriormost and anterior parapodia (Fig. 5F), with proximal half 1.2-1.4 times as wide as notoaciculae.

NotochaETAE. All homogomph spinigers (Fig. 5J); 18-20 spinigers present in anterior parapodia, 13-16 spinigers in middle parapodia, 5-9 spinigers in posterior parapodia.

SUPRACICULAR NEUROCHAETAE. Consisting of homogomph spinigers and heterogomph falcigers (Fig. 5K), both present throughout; 5-6 spinigers in anteriormost parapodia, 11-12 spinigers in anterior parapodia, 6-9 spinigers in middle parapodia, 4-7 spinigers in posterior parapodia; 3-4 falcigers present in anteriormost and anterior parapodia, 2-3 falcigers in middle parapodia, 1-2 falcigers in posterior parapodia.

Subacicular neurochaetae. Consisting of heterogomph spinigers (Fig. 5L) and heterogomph falcigers (Fig. 5M), both present throughout; 4-5 spinigers in anteriormost parapodia, 6-8 spinigers in anterior and middle parapodia, 3-4 spinigers in posterior parapodia; 7-8 falcigers in anteriormost parapodia, 9-10 falcigers in anterior parapodia, 6-8 falcigers in middle parapodia, 3-4 falcigers in posterior parapodia.

BLADES. Both homogomph (Fig. 5J) and heterogomph (Fig. 5L) spinigers with blades finely serrated towards toothed edge, evenly spaced, long ( $B / A$ ratio 10.9-22.5). Heterogomph falcigers with blades of medium and long sizes ( $B / A$ ratio 1.7-2.3), slender, convex, terminal tooth blunt with inconspicuous tendon; serrations present in about half to two-fifths (0.39-0.48; Fig. 5K, M) of total blade length. Shaft of supracicular falcigers thicker than subacicular ones in posterior parapodia; camerated, with cavity divided sub-distally into two longitudinal partitions (Fig. 5M).

Pygidium. In regeneration, with anal cirri as long as last 6 chaetigers; cirrophores of anal cirri barely developed.

\section{Remarks}

Among all the currently know species of Neanthes, N. mossambica from Mozambique resembles $N$. chilkaensis from India, $N$. indica brunnea from Mozambique, and $N$. talehsapensis from the Gulf of Thailand. These species share proximal region of dorsal ligule of similar size throughout the body (or slightly enlarged in posterior parapodia), presence of neuropodial postchaetal and notopodial prechaetal lobes at least in some anterior chaetigers, absence of neuropodial superior lobes, areas VII-VIII with two well-defined bands of more than 20 paragnaths, and area I with two or more paragnaths (see VillalobosGuerrero \& Idris 2021: table 2).

Nonetheless, $N$. mossambica is distinguishable from them all by the following diagnostic features: (I) one paragnath on area VI, in contrast to 5-7 in $N$. chilkaensis, 4-6 in $N$. indica brunnea, 4-5 in 

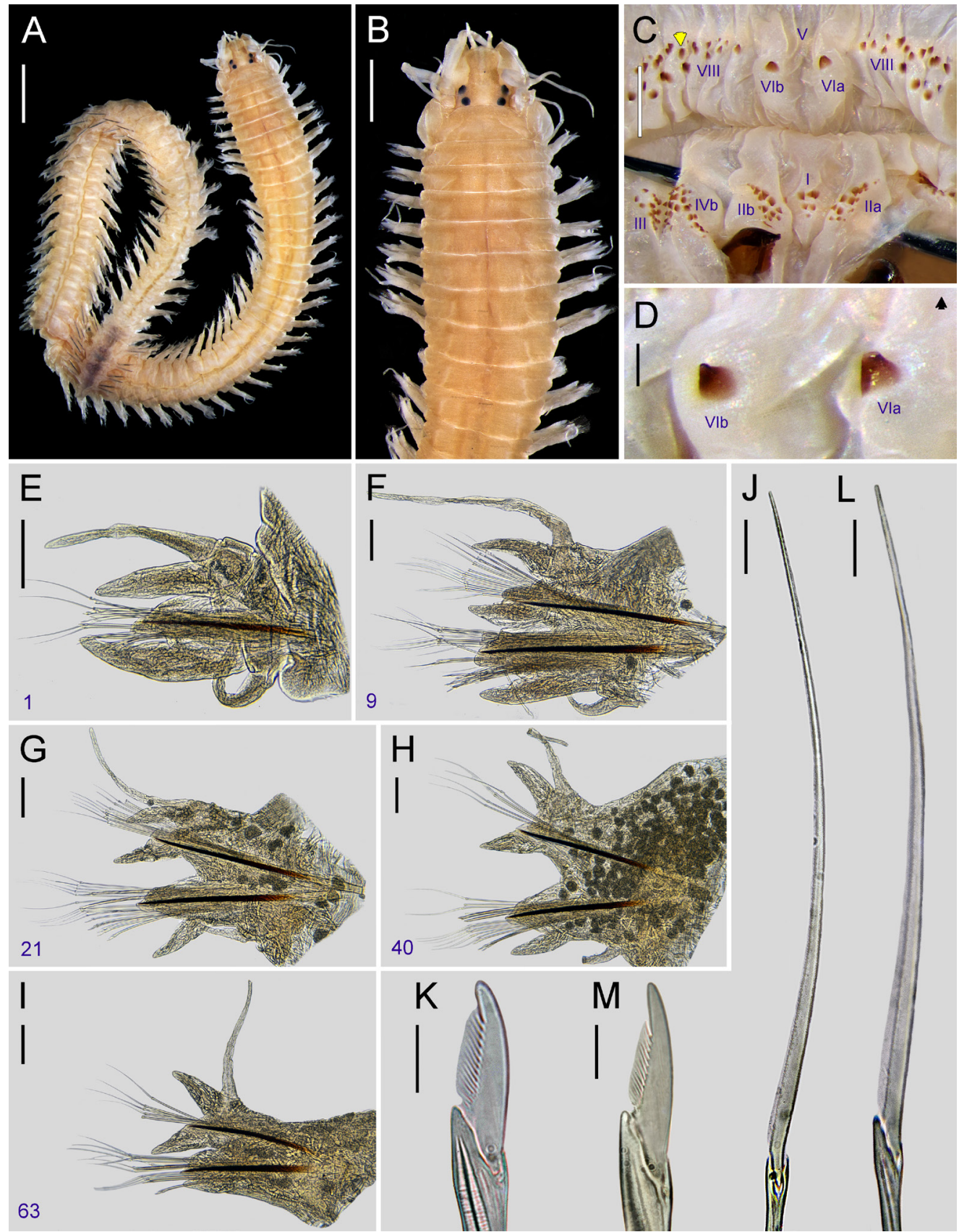

Fig. 5. Neanthes mossambica (Day, 1957). Holotype (NHMUK 1961.16.22) from Morrumbene, Mozambique, atokous female. A. Entire body in dorsal view. B. Anterior end in dorsal view. C. Noneverted pharynx in ventral view (arrow indicates p-bar). D. Area VI of non-everted pharynx in ventral view (arrow pointing anteriorly). E. Left parapodium from chaetiger 1 in posterior view. F. Right parapodium from chaetiger 9 in anterior view. G. Left parapodium from chaetiger 21 in posterior view. H. Right parapodium from chaetiger 40 in anterior view. I. Right parapodium from chaetiger 63 in anterior view with ventral cirri contracted and hidden behind the neuroacicular ligule. J. Homogomph spiniger from notochaetae (chaetiger 9). K. Heterogomph spiniger from subacicular neurochaetae (chaetiger 9). L. Heterogomph falciger from supracicular neurochaetae (chaetiger 9). M. Heterogomph falciger from subacicular neurochaetae (chaetiger 9). Roman numerals refer to the areas and Arabic numbers to chaetigers. Scale bars: $A=2 \mathrm{~mm} ; B=1 \mathrm{~mm} ; C=0.5 \mathrm{~mm} ; \mathrm{D}=0.1 \mathrm{~mm} ; \mathrm{E}-\mathrm{I}=0.2 \mathrm{~mm}$; $\mathrm{J}-\mathrm{M}=20 \mu \mathrm{m}$. 
$N$. talehsapensis; (II) the absence of oesophageal caeca, in contrast to its presence in N. chilkaensis and $N$. indica brunnea; (III) the area VI with conical paragnaths only, in contrast to both conical and p-bars in N. chilkaensis; (IV) the smooth tentacular cirri, in contrast to multi-articulated in N. chilkaensis; (V) the area V without paragnaths, in comparison to their presence in N. chilkaensis; (VI) the area VIIVIII with conical paragnaths only, in comparison to p-bars only in N. chilkaensis; (VII) the prostomium longer than wide, in contrast to that as long as wide in N. talehsapensis; (VIII) the aciculae mostly black, in contrast to those rather pale colour in N. talehsapensis; (IX) the notopodial prechaetal lobes distinctly smaller than median ligule throughout, in contrast to those that are subequal in anterior chaetigers of $N$. talehsapensis; (X) 23-32 paragnaths on area III, in comparison to 5-9 in N. indica brunnea; (XI) the dorsal cirri extending markedly beyond distal region of dorsal ligule, in contrast to those not extending beyond in N. indica brunnea; (XII) the presence of neuropodial postchaetal lobe throughout, in contrast to that in anterior chaetigers only in $N$. indica brunnea; (XIII) the heterogomph falciger blades with blunt terminal tooth and inconspicuous tendon in middle and posterior parapodia, in contrast to those with hammer-headed terminal tooth and distinct tendon in $N$. indica brunnea; (XIV) the antennae well separated from each other, in comparison to those closely together in N. indica brunnea; and (XV) the dorsum of segments with pigmentation bands, in contrast to a pigment band present only in the apodous segment of $N$. indica brunnea.

Neanthes mossambica was briefly described, scarcely illustrated and placed within the subgenus Nereis (Neanthes) by Day (1957) using two atokous specimens collected from the Morrumbene Estuary, Mozambique. Both the holotype and paratype match the original description. The species has always been considered within Neanthes, either recognized at the subgeneric (Hartman 1959; Day 1967; Raghunath 1976) or generic (Pillai 1965; Fauchald 1972; Wilson 1984) level, except Day (1974) who for an unknown reason enlisted the species as Nereis mossambica. The combination Neanthes mossambica that prevails nowadays was used for the first time by Pillai (1965) while comparing his new species Neanthes manatensis from Manat, Philippines. Both species are morphologically similar, however, as Pillai (1965) aptly mentioned, they can be distinguished by the number of paragnaths on the area I, and also on areas III and VII-VIII.

Neanthes mossambica was briefly characterised by Day (1967) but based solely on the original description. No more attempt to describe the morphology of the species was performed. The original description includes a short, implicit comparison with three other Neanthes species (formerly in Nereis): Neanthes chilkaensis, N. talehsapensis, and N. glandicincta (Southern, 1921) from near Calcutta, India. The first two species were distinguished above in detail from N. mossambica. Neanthes glandicincta was recently redescribed using a syntype and specimens from Myanmar and Singapore (Lee \& Glasby 2015) and characterised with individuals from Malaysia and Thailand (Ibrahim et al. 2019; Azmi et al. 2021). Neanthes mossambica can be easily distinguished from $N$. glandicincta by the absence of neuropodial superior lobe (present in N. glandicincta), the presence of two bands of paragnaths on area VII-VIII (one or none bands in $N$. glandicincta), the presence of heterogomph falcigers throughout the body (absent in anterior parapodia in $N$. glandicincta), among other features.

The species has been recorded in India (Raghunath 1976) and Bangladesh (Muir \& Hossain 2014), although these records are questionable since no species' characterisations were provided.

\section{Distribution}

Mozambique: Tinga-Tinga and Fern Bank, both in Morrumbene Estuary (Day 1974).

\section{Ecology}

Estuarine habitats, among mangrove swamps (Day 1974). 


\section{Reproduction}

Unknown.

\section{Discussion}

Four species of Neanthes, $N$. chilkaensis, N. galetae, N. helenae and N. mossambica, are redescribed. Diagnostic features are illustrated, and habitat, distribution and taxonomic remarks are given for the species.

Redescriptions based on the type material permit to recognize species as valid. These four species were poorly or not distinguished from others in the original descriptions. The current study provides sufficient evidence to warrant their separation from other similar congeners. Detailed comparisons of the species using a combination of former and recent diagnostic characters enabled reliable differentiation. For instance, the typical characters related to the paragnaths and parapodial structures (Hartman 1954; Hutchings \& Turvey 1982; Wilson 1984; Wu et al. 1985; Khlebovich 1996; Bakken 2002, 2006; Glasby et al. 2011; Hsueh 2019a; Ibrahim et al. 2019), combined with the latest proposed ridge patterns on areas VI-V-VI and the occurrence of oesophageal caeca allow their distinction among Neanthes species.

Additionally, redescriptions also allow one to complete the species' description, delimit their morphology, and detect previously-overlooked or unique features. In this study, the presence of pointed bar-shaped paragnaths ('p-bars') on area VI of $N$. chilkaensis and $N$. helenae, as well as its sole presence on the areas VII-VIII in N. chilkaensis, is detected for the first time in the family Nereididae. The p-bar is a relatively recent paragnath term defined as a small bar with a protruding apex in one end (Bakken et al. 2009). It was first introduced for some species of Pseudonereis, which bear that type of paragnath on areas II, III, IV and VII-VIII (Bakken 2007). Later, the p-bars were also recorded on the oral ring of some species of Alitta (Villalobos-Guerrero \& Carrera-Parra 2015), Nereis (Conde-Vela \& SalazarVallejo 2015), and presently in Neanthes. Nonetheless, detailed studies on the genera are needed since the p-bars might have been described as conical paragnaths in earlier literature.

Moreover, $N$. helenae is unique within the genus by showing ventrolateral projections on the apodous segment. These are similar to the flap-like projections present in the species of Cheilonereis Benham, 1916 and Laevispinereis He \& Wu, 1989. The development of projections is dependent on the size of the specimens, as it becomes more expanded in larger individuals of Cheilonereis (Harrington 1897; Ramsay 1914). A similar pattern was observed in N. helenae, although the flap is less developed (Fig. 4C-D). Cheilonereis and Laevispinereis were mainly diagnosed by the presence of this structure, although other features in the parapodial lobes, ligules and chaetae were also found relevant to define their generic morphology (sensu Santos et al. 2005). Neanthes helenae is still retained in Neanthes as it resembles more to the type species, $N$. vaalii, than to C. cyclurus (Harrington, 1897) and L. fujianensis He \& Wu, 1989. For instance, $N$. helenae is similar to $N$. vaalii by having paragnaths on the oral ring, heterogomph falcigers in neuropodia, rounded and short neuropodial superior and inferior lobes and by lacking notopodial prechaetal and neuropodial postchaetal lobes, in comparison to L. fujianensis that has papillae on the oral ring, homogomph falcigers in neuropodia, conical and long notopodial and neuropodial lobes (He \& Wu 1989). Also, N. helenae is similar to $N$. vaalii by having spinigers only in notopodia and dorsal ligule of similar size throughout the body, in contrast to falcigers present in notopodia and dorsal ligule expanded in posterior notopodia in C. cyclurus. However, the re-allocation of $N$. helenae in another genus is not disregarded after the revision of Neanthes is developed considering its polyphyletic status.

Further descriptive work is necessary for a complete survey of the characters in Neanthes. A better understanding of the morphology of characters and their potential in phylogenetic analyses are warranted for the urgent revision of the genus. Currently-common characters often not included in the original 
descriptions or overlooked in the redescriptions should be considered, such as articulations on tentacular cirri, merged paragnaths on area IV, and laterally isolated paragnaths on area III, among others. Likewise, particular attention should be paid to those recently proposed, as species beyond the four redescribed here and other four elsewhere (see Villalobos-Guerrero \& Idris 2021) remain mostly unknown.

\section{Acknowledgements}

We are very thankful to the following curators and collection managers for granting access to the collections under their care: Leslie Harris and Kirk Fitzhugh (LACM-AHF), Emma Sherlock (NHMUK), Wayne Florence, Albé Bosman and Dylan Clarke (SAM), Lena Gustavsson (SMNH), and Karen Osborn, Kathryn Ahlfeld, and Geoff Keel (USNM). TFVG is grateful to Birger Neuhaus (ZMB) and Luis F. Carrera-Parra (ECOSUR) for their kind support provided in their research laboratories and facilitating access to materials from other museums' collections. Last but not least, we also appreciate the valuable recommendations provided by Torkild Bakken and one anonymous reviewer to improve this contribution. The first author was supported by the German Academic Exchange Service (DAAD) under the grant number 91673478 and by the Consejo Nacional de Ciencia y Tecnología (CONACYT) under the grants nos 291062, 291212.

\section{References}

Azmi S.S., Ibrahim Y.S., Angsupanich S., Sumpuntarat P. \& Sato M. 2021. Epitokous metamorphosis, reproductive swimming, and early development of the estuarine polychaete, Neanthes glandicincta Southern, 1921 (Annelida, Nereididae) on the east coast of the Malay Peninsula. ZooKeys 1011: 1-24. https://doi.org/10.3897/zookeys.1011.59780

Bakken T. 2002. A new species of Neanthes (Polychaeta: Nereididae) from southern Australia. Memoirs of the Museum of Victoria 59 (2): 327-331. http://doi.org/10.24199/j.mmv.2002.59.4

Bakken T. 2006. Redescription of two species of Neanthes (Polychaeta: Nereididae) possessing a large notopodial prechaetal lobe. Scientia Marina 70 (S3): 27-33. https://doi.org/10.3989/scimar.2006.70s327

Bakken T. 2007. Revision of Pseudonereis (Polychaeta, Nereididae). Zoological Journal of the Linnean Society 150: 145-176. https://doi.org/10.1111/j.1096-3642.2007.00289.x

Bakken T. \& Wilson R.S. 2005. Phylogeny of nereidids (Polychaeta, Nereididae) with paragnaths. Zoologica Scripta 34: 507-547. https://doi.org/10.1111/j.1463-6409.2005.00200.x

Bakken T., Glasby C.J. \& Wilson R.S. 2009. Areview of paragnath morphology in Nereididae (Polychaeta). Zoosymposia 2: 305-316. https://doi.org/10.11646/zoosymposia.2.1.21

Bakken T., Glasby C.J., Santos C.S.G. \& Wilson R.S. 2018. Nereididae Blainville, 1818. In: Westheide W., Purschke G. \& Böggemann M. (eds) Handbook of Zoology. A Natural History of the Phyla of the Animal Kingdom, Annelida: Polychaetes. De Gruyter, Ösnabruck.

Conde-Vela V.M. 2018. New species of Pseudonereis Kinberg, 1865 (Polychaeta: Nereididae) from the Atlantic Ocean, and a review of paragnath morphology and methodology. Zootaxa 4471: 245-278. https://doi.org/10.11646/zootaxa.4471.2.2

Conde-Vela V.M. \& Salazar-Vallejo S.I. 2015. Redescriptions of Nereis oligohalina (Rioja, 1946) and N. garwoodi González-Escalante \& Salazar-Vallejo, 2003 and description of $N$. confusa sp. n. (Annelida, Nereididae). ZooKeys 518: 15-49. https://doi.org/10.3897/zookeys.518.9564

Davenport J.S., Glasby C.J. \& Karlen D.J. 2020. Redescription of Neanthes micromma Harper, 1979 (Annelida: Nereididae) based on types and additional material from Tampa Bay, Florida, USA, with a discussion of ontogenetic morphological variation. Zoosymposia 19: 135-150.

https://doi.org/10.11646/zoosymposia.19.1.15 
Day J.H. 1949. On the Polychaeta collected by Mr. J. Colman at St. Helena. Journal of the Linnean Society of London, Zoology 41 (281): 434-451. https://doi.org/10.1111/j.1096-3642.1940.tb02416.x

Day J.H. 1957. The Polychaete Fauna of South Africa, 4. New species and records from Natal and Moçambique. Annals of the Natal Museum 14 (1): 59-129.

Day J.H. 1967. A Monograph on the Polychaeta of Southern Africa, Part 1. Errantia. British Museum (Natural History) Publication 656, London. https://doi.org/10.5962/bhl.title.8596

Day J.H. 1974. The ecology of Morrumbene Estuary, Moçambique. Transactions of the Royal Society of South Africa 41 (1): 43-97. https://doi.org/10.1080/00359197409519438

de León-González J.A., Villalobos-Guerrero T.F. \& Conde-Vela V.M. 2020. Nereididae de Blainville, 1818. In: de León-González J.A., Bastida-Zavala J.R., Carrera-Parra L.F., García-Garza M.E., SalazarVallejo S.I., Solís-Weiss V., Tovar-Hernández M.A. (eds) Poliquetos (Annelida: Polychaeta) de México y América Tropical, $2^{a}$ Ed. Universidad Autónoma de Nuevo León, Monterrey, México.

de Silva P.H.D.H. 1965. New species and records of Polychaeta from Ceylon. Proceedings of the Zoological Society of London 144 (4): 537-563. https://doi.org/10.1111/j.1469-7998.1965.tb05196.x

Fauchald K. 1972. Benthic polychaetous annelids from deep water off western Mexico and adjacent areas in the Eastern Pacific Ocean. Allan Hancock Foundation Monographs in Marine Biology 7: 1-575. Available from https://repository.si.edu/handle/10088/6207 [accessed 1 Jul. 2021].

Fauchald K. 1977. Polychaetes from intertidal areas in Panama, with a review of previous shallow-water records. Smithsonian Contributions to Zoology 221: 1-81. https://doi.org/10.5479/si.00810282.221

Fauvel P. 1932. Annelida Polychaeta of the Indian Museum, Calcutta. Memoirs of the Indian Museum 12: $1-262$.

Fauvel P. 1940. On a small collection of Annelida Polychaeta of the Indian Museum, Calcutta. Records of the Indian Museum 422: 253-568.

Fauvel P. 1953. The Fauna of India including Pakistan, Ceylon, Burma and Malaya: Annelida, Polychaeta. Indian Press, Allahabad.

Fitzhugh K. 1987. Phylogenetic relationships within the Nereididae (Polychaeta): implications at the subfamily level. Bulletin of the Biological Society of Washington 7: 174-183.

Ganapati P.N. 1946. On Lecudina pellucida (Kölliker) Mingazzini (1891) from the gut of Nereis chilkaensis Southern. Proceedings of the Indian Academy of Sciences, Section B 23: 211-227.

Glasby C.J. 2015. Nereididae (Annelida: Phyllodocida) of Lizard Island, Great Barrier Reef, Australia. Zootaxa 4019 (1): 207-239. https://doi.org/10.11646/zootaxa.4019.1.11

Glasby C.J. \& Hsieh H.L. 2006. New species and new records of the Perinereis nuntia species group (Nereididae: Polychaeta) from Taiwan and other Indo-West Pacific shores. Zoological Studies 45: 553577.

Glasby C.J., Wilson R.S. \& Bakken T. 2011. Redescription of the Indo-Pacific polychaete Neanthes pachychaeta (Fauvel, 1918) n. comb. (Annelida, Phyllodocida, Nereididae) and its synonyms. Zoosystema 33: 361-375. https://doi.org/10.5252/z2011n3a5

Harrington N.R. 1897 On nereids commensal with hermit crabs. Transactions of the New York Academy of Sciences 16: 214-222.

Hartman O. 1940. Polychaetous annelids. Part 2. Chrysopetalidae to Goniadidae. Allan Hancock Pacific Expeditions 7: 173-287. 
Hartman O. 1954. Australian Nereidae, including descriptions of three new species and one genus, together with summaries of previous records and keys to species. Transactions of the Royal Society of South Australia 77: 1-41.

Hartman O. 1959. Catalogue of the polychaetous annelids of the world, 1. Occasional Papers of the Allan Hancock Foundation 23: 1-353.

Hartman O. 1974. Polychaetous annelids of the Indian Ocean including an account of species collected by members of the International Indian Ocean Expeditions, 1963-1964 and a catalogue and bibliography of the species from India, Part 2. Journal of the Marine Biological Association of India 16: 609-644.

Hartmann-Schröder G. 1975. Polychaeten der Iberischen Tiefsee, gesammelt auf der 3. Reise der Meteor im Jahre 1966. Mitteilungen aus dem Hamburgischen zoologischen Museum und Institut 72: 47-73.

Hartmann-Schröder G. 1996. Annelida, Borstenwürmer, Polychaeta [Annelida, bristleworms, Polychaeta], $2^{\text {nd }} E d$. The Fauna of Germany and adjacent Seas with their Characteristics and Ecology, 58. Gustav Fischer, Jena.

He M. \& Wu Q. 1989. A new genus and a new species of Nereidae. Acta Oceanologica Sinica 8: 441-443.

Hsueh P.W. 2019a. Neanthes (Annelida: Nereididae) from Taiwanese waters, with description of seven new species and one new species record. Zootaxa 4554 (1):173-198.

https://doi.org/10.11646/zootaxa.4554.1.5

Hsueh P.W. 2019b. Two new species of nereidids (Annelida, Polychaeta) from Taiwan. Zootaxa 4652 (3): 544-556. https://doi.org/10.11646/zootaxa.4652.3.10

Hutchings P.A. \& Turvey S.P. 1982. The Nereididae of South Australia. Transactions of the Royal Society of South Australia 106 (3): 93-144.

Ibrahim N.F., Ibrahim Y.S. \& Sato M. 2019. New record of an estuarine polychaete, Neanthes glandicincta (Annelida, Nereididae) on the eastern coast of Peninsular Malaysia. ZooKeys 831: 81-94.

https://doi.org/10.3897/zookeys.831.28588

Jaime R., Cantera K., Thomassin B.A. \& Arnaud P.M. 1999. Faunal zonation and assemblages in the Pacific Colombian mangroves. Hydrobiologia 413: 17-33.https://doi.org/10.1007/978-94-011-4078-2_3

Jansonius J. \& Craig J.H. 1971. Scolecodonts: I. Descriptive terminology and revision of systematic nomenclature; II. Lectotypes, new names for homonyms, index of species. Bulletin of Canadian Petroleum Geology 19: 251-302.

Khlebovich V.V. 1996. Fauna of Russia and neighbouring countries. Polychaetous Annelids, Volume III. Polychaetes of the family Nereididae of the Russian seas and the adjacent waters. Proceedings of the Zoological Institute of the Russian Academy of Sciences 140: 1-221. [In Russian.]

Kinberg J.G.H. 1865. Annulata nova. Nereidum dispositio nova. Öfversigt af Kongelige VetenskapsAkademiens Förhandlingar 22: 167-179. Available from https://www.biodiversitylibrary.org/page/32339443 [accessed 1 Jul. 2021].

Lee Y.L. \& Glasby C.J. 2015. A new cryptic species of Neanthes (Annelida: Phyllodocida: Nereididae) from Singapore confused with Neanthes glandicincta Southern, 1921 and Ceratonereis (Composetia) burmensis (Monro, 1937). Raffles Bulletin of Zoology 31:75-95.

Markande A.R., Mikaelyan A., Bhusan B., Patel K.D., Vachharajani N.B., Vennila A., Valappil R.A. \& Purushothaman C.S. 2014. Analysis of midgut bacterial community structure of Neanthes chilkaensis from polluted mudflats of Gorai, Mumbai, India. Advances in Microbiology 4 (13): 906-918.

https://doi.org/10.4236/aim.2014.413101 
Misra A., Chakraborty R.K. \& Soota T.D. 1987. Polychaeta. In: Director (ed.) Zoological Survey of India, Calcutta, Series 1: 69-89. State Fauna Series, Fauna of Orissa.

Muir A. \& Hossain M. 2014. The intertidal polychaete (Annelida) fauna of the Sitakunda coast (Chittagong, Bangladesh), with notes on the Capitellidae, Glyceridae, Lumbrineridae, Nephtyidae, Nereididae and Phyllodocidae of the "Northern Bay of Bengal Ecoregion". ZooKeys 419: 1-27. https://doi.org/10.3897/zookeys.419.7557

Nageswara Rao C.A. 1995. Annelida: Polychaeta. In: Director (ed.) Wetland Ecosystem Series, Fauna of Chilka Lake: 319-325. Zoological Survey of India, Calcutta.

Nesemann H. \& Sharma S. 2007. Class Polychaeta. In: Nesemann H., Sharma S., Sharma G., Khanal S.N., Pradhan B., Shah D.N. \& Tachamo R.D. (eds) Aquatic Invertebrates of the Ganga River System (Mollusca, Annelida, Crustacea [in part]). Volume 1: 103-110. Chandi Media Pvt. Ltd, Nepal.

Pamungkas J. \& Glasby C.J. 2015. Taxonomy of reproductive Nereididae (Annelida) in multispecies swarms at Ambon Island, Indonesia. ZooKeys 520: 1-25. https://doi.org/10.3897/zookeys.520.9581

Parulekar A.H. 1971. Polychaetes from Maharashtra and Goa. Journal of the Bombay Natural History Society 68: 726-749.

Pati S.K., Swain D., Sahu K.C. \& Sharma R.M. 2015. Diversity and distribution of polychaetes (Annelida: Polychaeta) along Maharashtra coast, India. In: Rawat M., Dookia S. \& Sivaperuman C. (eds) Aquatic Ecosystem: Biodiversity, Ecology and Conservation: 53-65. Springer, New Delhi, India. https://doi.org/10.1007/978-81-322-2178-4_5

Pillai T.G. 1965. Annelida Polychaeta from the Philippines and Indonesia. Ceylon Journal of Science, Biological Sciences 5 (2): 110-177.

Planas A.O., Tejada A.L., Tejada O.L. \& Campos C.G. 2013. Epibiontes en las raíces de Rhizophora spp. en el manglar Barra de Santiago, Departamento de Ahuachapán, El Salvador. Puente Biológico 5: $11-49$.

Raghunath B. 1976. Occurrence of Nereis (Neanthes) mossambica in Indian waters. Current Science 45 (3): 102.

Ramsay L.N.G. 1914. On the annelids of the family Nereidae collected by Mr. F. A. Potts in the N.E. Pacific, in 1911. - With a note on the morphology of Micronereis as a representative of the ancestral type of the Nereidae. Proceedings of the Zoological Society of London 84 (2): 237-250.

https://doi.org/10.1111/j.1469-7998.1914.tb07033.x

Salazar-Vallejo S.I. \& Eibye-Jacobsen D. 2012. Annulata örstediana: publication dates, composition and annotated taxonomic list, with some comments on Hemipodus (Polychaeta: Glyceridae). Revista de Biología Tropical 60 (3): 1391-1402. https://doi.org/10.15517/rbt.v60i3.1815

Santos C.S.G., Pleijel F., Lana P. \& Rouse G.W. 2005. Phylogenetic relationships within Nereididae (Annelida: Phyllodocida). Invertebrate Systematics 19: 557-576. https://doi.org/10.1071/IS05001

Sato M. 2013. Resurrection of the genus Nectoneanthes Imajima, 1972 (Nereididae: Polychaeta), with redescription of Nectoneanthes oxypoda (Marenzeller, 1879) and description of a new species, comparing them to Neanthes succinea (Leuckart, 1847). Journal of Natural History 47 (1-2): 1-50. https://doi.org/10.1080/00222933.2012.743609

Sato M. 2020. Two new species of Composetia (Annelida: Nereididae) from small estuaries in the Ryukyu Islands, southern Japan, with a list of all species currently belonging to Composetia. Species Diversity 25: 11-24. https://doi.org/10.12782/specdiv.25.11 
Shimabukuro M., Santos C.S.G., Alfaro-Lucas J.M., Fujiwara Y. \& Sumida P.Y.G. 2017. A new eyeless species of Neanthes (Annelida: Nereididae) associated with a whale-fall community from the deep Southwest Atlantic Ocean. Deep Sea Research Part II: Topical Studies in Oceanography 146: 27-34. https://doi.org/10.1016/j.dsr2.2017.10.013

Southern R. 1921. Polychaeta of the Chilka Lake and also of fresh and brackish waters in other parts of India. Memoirs of the Indian Museum 5:563-659.

Sunder Raj S.K. \& Sanjeeva Raj P.J. 1987. Polychaeta of the Pulicat Lake (Tamil Nadu). Journal of the Bombay Natural History Society 84 (1): 84-104.

van Soest R.W.M., Boury-Esnault N., Hooper J.N.A., Rützler K., de Voogd N.J., Alvarez B., Hajdu E., Pisera A.B., Manconi R., Schönberg C., Klautau M., Kelly M., Vacelet J., Dohrmann M., Díaz M.-C., Cárdenas P., Carballo J.L., Ríos P., Downey R. \& Morrow C.C. 2020. Laxosuberites Topsent, 1896. World Porifera Database. Available from http://www.marinespecies.org/aphia.php? $\mathrm{p}=$ taxdetails\&id=132066 [accessed 13 Jan. 2021].

Vásquez Montoya R. \& Thomassin B. 1983. Contribución al conocimiento de los anélidos poliquetos de las praderas de Thalassia testudinum y Halodule sp. del sector de Punta Galeta (Panamá, Provincia de Colón). Anales del Instituto de Ciencias del Mar y Limnología, UNAM 10: 1-10.

Villalobos-Guerrero T.F. 2019. Redescription of two overlooked species of the Perinereis nuntia complex and morphological delimitation of P. nuntia (Savigny in Lamarck, 1818) from the Red Sea (Annelida, Nereididae). Zoosystema 41: 465-496. https://doi.org/10.5252/zoosystema2019v41a24

Villalobos-Guerrero T.F. \& Bakken T. 2018. Revision of the Alitta virens species complex (Annelida: Nereididae) from the North Pacific Ocean. Zootaxa 4483: 201-257.

https://doi.org/10.11646/zootaxa.4483.2.1

Villalobos-Guerrero T.F. \& Carrera-Parra L.F. 2015. Redescription of Alitta succinea (Leuckart, 1847) and reinstatement of A. acutifolia (Ehlers, 1901) n. comb. based upon morphological and molecular data (Polychaeta: Nereididae). Zootaxa 3919: 157-178. https://doi.org/10.11646/zootaxa.3919.1.7

Villalobos-Guerrero T.F. \& Idris I. 2020. Redescriptions of a neglected species of Pseudonereis Kinberg, 1865 (Annelida: Nereididae) and its similar congener from the Eastern Tropical Pacific. Journal of Natural History 54: 1559-1580. https://doi.org/10.1080/00222933.2020.1810800

Villalobos-Guerrero T.F. \& Idris I. 2021. Reproductive morphology and redescriptions of some Neanthes Kinberg, 1865 (Annelida: Nereididae) species from the southeastern Asian seas, with comparative synoptic tables of accepted species. The European Zoological Journal 88 (1): 556-594. https://doi.org/10.1080/24750263.2021.1899318

Villalobos-Guerrero T.F., Park T. \& Idris I. 2021. Review of some Perinereis Kinberg, 1865 (Annelida: Nereididae) species of the Group 2 sensu Hutchings, Reid \& Wilson, 1991 from the Eastern and Southeastern Asian seas. Journal of the Marine Biological Association of the United Kingdom 1-29. https://doi.org/10.1017/S0025315421000126

Wilson R.S. 1984. Neanthes (Polychaeta: Nereididae) from Victoria with descriptions of two new species. Proceedings of the Royal Society of Victoria 96: 209-226.

Wu B.L., Sun R. \& Yang D.J. 1985. The Nereidae (Polychaetous Annelids) of the Chinese coast. China Ocean Press, Beijing. [English translation from the original, in Chinese, published in 1981] 
Published on: 22 July 2021

Topic editor: Rudy Jocqué

Desk editor: Pepe Fernández

Printed versions of all papers are also deposited in the libraries of the institutes that are members of the EJT consortium: Muséum national d'histoire naturelle, Paris, France; Meise Botanic Garden, Belgium; Royal Museum for Central Africa, Tervuren, Belgium; Royal Belgian Institute of Natural Sciences, Brussels, Belgium; Natural History Museum of Denmark, Copenhagen, Denmark; Naturalis Biodiversity Center, Leiden, the Netherlands; Museo Nacional de Ciencias Naturales-CSIC, Madrid, Spain; Real Jardín Botánico de Madrid CSIC, Spain; Zoological Research Museum Alexander Koenig, Bonn, Germany; National Museum, Prague, Czech Republic. 